\title{
Effectiveness of Responsivity Intervention Strategies on Prelinguistic and Language Outcomes for Children with Autism Spectrum Disorder: A Systematic Review and Meta-Analysis of Group and Single Case Studies
}

\author{
Jena McDaniel ${ }^{1}$ (D) Nancy C. Brady ${ }^{2}$ Steven F. Warren²
}

Accepted: 15 October 2021 / Published online: 15 November 2021

(c) The Author(s) 2021

\begin{abstract}
We conducted a systematic review to identify randomized controlled trials (RCTs) and single case research design (SCRD) studies of children with autism spectrum disorder that evaluate the effectiveness of responsivity intervention techniques for improving prelinguistic and/or language outcomes. Mean effect sizes were moderate and large for RCTs (33 studies; $g=0.36$, 95\% CI [0.21, 0.51]) and SCRD (34 studies; between-case standardized mean difference $=1.20,95 \%$ CI $[0.87,1.54]$ ) studies, respectively. Visual analysis (37 studies) revealed strong evidence of a functional relation for $45 \%$ of the opportunities and no evidence for $53 \%$. Analyses of moderator effects and study quality are presented. Findings provide support for responsivity intervention strategies with more robust support for context-bound outcomes than more generalized outcomes.
\end{abstract}

Keywords Autism spectrum disorder $\cdot$ Language $\cdot$ Meta-analysis $\cdot$ Prelinguistic $\cdot$ Responsivity

Children with autism spectrum disorder (ASD) exhibit difficulty learning language with wide variation in the nature and degree of these difficulties (Kjelgaard \& Tager-Flusberg, 2001; Lord et al., 2004; Tager-Flusberg et al., 2005; Thurm et al., 2007). Concerns with communication are often one of the first developmental concerns that caregivers of children later diagnosed with ASD express (De Giacomo, \& Fombonne, 1998; Howlin \& Moore, 1997; Kozlowski et al., 2011). Such concerns are consistent with the observed areas of need in prelinguistic skills of children with ASD (e.g., joint attention, canonical babbling; Mundy et al., 1986;

Content from this manuscript has been presented at the 2021 Gatlinburg Conference on Research and Theory in Intellectual and Developmental Disabilities, 2021 International Society for Autism Research Annual Meeting, and the 2021 Symposium on Research in Child Language Disorders.

Jena McDaniel

jena.c.mcdaniel@ku.edu

1 Life Span Institute, University of Kansas, 3001 Dole Human Development Center, 1000 Sunnyside Ave, Lawrence, KS 66045-7555, USA

2 Department of Speech-Language-Hearing: Sciences \& Disorders, University of Kansas, Lawrence, KS, USA
Patten et al., 2014; Sigman \& Ruskin, 1999). Approximately $30 \%$ of children with ASD present with minimal verbal skills, using only a few words, even after years of intervention (Anderson et al., 2007; Tager-Flusberg \& Kasari, 2013). Other individuals with ASD achieve fluent speech with large vocabularies and complete sentences (Kjelgaard \& TagerFlusberg, 2001; Tager-Flusberg \& Joseph, 2003). Pragmatic language, which includes the social aspects of language, has been identified as a particular area of need for children with ASD (Lord \& Paul, 1997; Wilkinson, 1998). These language difficulties may have long-term negative consequences on social and vocational outcomes, including decreased likelihood of living independently and low employment status (Billstedt et al., 2005; Howlin, 2000). Thus, determining how to best mitigate such difficulties is critical for improving long-term outcomes of individuals with ASD.

Interventions for children with ASD vary across multiple facets including theoretical basis, type of interventionist (e.g., clinicians, caregivers, peers, or their combination), degree to which interventions are child-led versus adult-led (i.e., directedness), and how the communication partner responds to communicative attempts. Investigations of the effectiveness of communication and language interventions have yielded widely varying results (e.g., Hampton \& 
Kaiser, 2016; Reichow et al., 2018; Sandbank et al., 2020b). Because intervention studies vary in many factors (e.g., participants characteristics, outcome measures, and intervention features), systematic synthesis across studies is needed to draw conclusions. One synthesis approach is to evaluate interventions with specific components to identify active ingredients of effective interventions. This approach may enable interventionists to focus on the essential strategies. Focusing on essential strategies is especially important when caregivers serve as the interventionist because teaching too many strategies or tasks may risk overwhelming caregivers and reducing the training's effectiveness. This systematic review and meta-analysis synthesizes and evaluates studies of interventions that use responsivity intervention strategies to target prelinguistic and language skills in children with ASD.

\section{Responsivity Intervention Strategies}

We define responsivity intervention strategies as strategies designed to support the development of turn-taking conversations through setting up the environment to increase communication by following the child's lead, using natural reinforcement for communicative attempts, and providing targeted input. The adult adapts their responses to the child's focus of attention and/or on-going actions. Responsive strategies include, but are not limited to, linguistic mapping, follow-in comments, recasting, and imitating the child. Linguistic mapping occurs when an adult describes the child's action and/or underlying message or intention (Yoder \& Warren, 2002). For example, the adult says, "That's a book," when the child points to a book and says, "Uh". Followin comments describe the child's current focus of attention (McDuffie \& Yoder, 2010). For example, the adult says, "That car is going fast," when the child is playing with a toy car. When an adult recasts what a child says, they add grammatical or phonemic information to the child's utterance. For example, the adult says, "That dog is big!" when the child comments, "Dog big." When imitating a child, the adult may imitate the child's words, sounds, gestures, and/or actions on objects. These responsivity intervention strategies can, and often do, target prelinguistic skills (e.g., joint attention and vocalizations) that are foundational to language use and conversational turn-taking.

Responsivity intervention strategies may be used independently, but they are often used within an intervention package, such as a naturalistic developmental behavioral intervention (NDBI). NDBIs combine developmental principles and applied behavior analysis (ABA) principles, follow the child's lead, and include multiple intervention strategies to support learning and engagement (Schreibman et al., 2015). Examples include the Early Start Denver Model (ESDM), Joint Attention
Symbolic Play Engagement and Regulation (JASPER), Pivotal Response Treatment (PRT), reciprocal imitation training (RIT), and Responsivity Education / Prelinguistic Milieu Teaching (RE/PMT). Responsivity intervention strategies contrast adult-driven interventions that emphasize discrete training of specific behaviors using structured prompting procedures (e.g., discrete trial training).

Responsivity intervention strategies align with multiple theories that emphasize the bidirectional interactions between children and adults in facilitating vocal and language development, including the social feedback theory (Goldstein \& Schwade, 2008; Goldstein et al., 2003), social feedback loop theory (Warlaumont et al., 2014), and transactional theory of spoken language development (Camarata \& Yoder, 2002; McLean \& Snyder-McLean, 1978; Sameroff \& Chandler, 1975). Although the details of these theories vary modestly, they all support the use of contingent caregiver responses to children's communicative attempts to facilitate continued growth in communication and language. Thus, these theories provide support for use of responsivity intervention strategies during language intervention for children with ASD.

The social feedback theory asserts that children produce more complex and more adult-like vocalizations when adults respond contingently to them within social interactions (e.g., smiling at, moving closer to, and/or touching the infant when they vocalize) than when they respond noncontingently (Goldstein et al., 2003). The contingent nature of the response is emphasized rather than a more general response style or the quantity of input. Intervention procedures that support adults consistently responding to child vocalizations, but not responding when the child is not producing vocalizations, would align with the social feedback theory.

The social feedback loop theory emphasizes that adults are more likely to respond to children's speechlike utterances than non-speechlike utterances and children are more likely to produce speechlike utterances when their communication partner responds to their immediately preceding utterance (Warlaumont et al., 2014). The social feedback loop theory aligns with intervention approaches that increase adults' responses to children's utterances as well as increasing the number of child vocalizations.

The transactional theory of spoken language development posits that caregivers provide increasingly complex input to the child as the child produces more complex communication and language acts. The relatively more complex input scaffolds continued child growth that evokes even more complex input (Camarata \& Yoder, 2002). Thus, this theory supports intervention strategies that encourage adults to provide input that is contingent on and somewhat more complex than the child's utterances. 


\section{Relevant Prior Reviews}

No known prior reviews specifically address the effects of responsivity intervention strategies on prelinguistic and language skills of children with ASD using randomized controlled trials (RCTs) and single case research design (SCRD) studies, which can address this causal question. One known systematic review and meta-analysis evaluated the effectiveness of intervention studies that addressed parent verbal responsiveness and child communication for children with or at risk for ASD (Edmunds et al., 2019). Because the meta-analysis only included five RCTs for the intervention studies, the results must be interpreted with caution. The findings identified improvement in parent verbal responsiveness but not child communication. Some of the included studies reported benefits for child communication but others did not. The limited number of studies available precluded more detailed analysis to explain the variation in results. Other reviews that have also focused on specific types of intervention (e.g., early intensive behavioral interventions [Reichow et al., 2018], parent-mediated early interventions [Oono et al., 2013], ESDM [Ryberg, 2015]) have been limited by the number and quality of relevant studies to include. These example meta-analyses included at most eight studies with at most two being RCTs.

Taking a different approach, a few other prior reviews have examined effects of broad language intervention for young children with ASD, regardless of the intervention type. These review studies were restricted to group design studies and have often included quasi-experimental studies in addition to randomized controlled trials (Hampton \& Kaiser, 2016; Sandbank et al., 2020a, 2020b). Sandbank and colleagues reported a positive, but small, statistically significant mean effect size for the effects of nonpharmacological early intervention on multiple areas of development, including language, for group design studies (Sandbank et al., 2020a, 2020b). Similarly, Hampton and Kaiser (2016) reported a small, significant mean overall effect size ( $g=0.26,95 \%$ CI $[0.11,0.42])$ for spoken language outcomes. Some reviews included children at risk for ASD, rather than only children diagnosed with ASD (Edmunds et al., 2019).

\section{Factors that May Influence the Presence and Strength of Intervention Effects}

Some of the reviews described above have investigated several factors that may influence the presence and strength of intervention effects. The results have often been mixed, which supports the need for continued investigation to reach a consensus. These variables include the interventionist, time in intervention, proximity of outcome measures, boundedness of outcome measures, risk of correlated measurement error, and publication bias.

\section{Interventionist}

ASD interventions may be implemented by a variety of individuals including caregivers, clinicians, and/or peers. Some interventions are implemented by multiple individuals, such as a caregiver and a clinician simultaneously with varying levels of caregiver training provided (e.g., Gengoux et al., 2019; Roberts et al., 2011; Vivanti et al., 2014). Logically, a child may benefit from both the caregiver spending relatively more time with the child during the day to implement therapeutic strategies and the clinician's expertise implementing and adapting strategies. Both Sandbank et al. (2020b) and Hampton and Kaiser (2016) reported stronger effects for intervention implemented by caregivers and clinicians than those implemented by caregivers alone. Sandbank et al. (2020b) also identified a larger effect size for interventions implemented by clinicians alone than those by caregivers alone, but Hampton and Kaiser (2016) did not find similar differences. Fuller and Kaiser (2020) did not identify a differential effect by interventionist. These three meta-analyses included responsive language interventions, but not exclusively.

\section{Time in Intervention}

School-based speech-language pathologists report providing more intensive intervention services for children with severe communication needs (Brandel \& Frome Loeb, 2011). Yet, there is relatively little relevant data regarding whether more intensive intervention yields greater language gains for children with ASD, despite its intuitive appeal (Baker, 2012; Warren et al., 2007). A number of meta-analyses have failed to identify total intervention dosage as a moderator of effect size for speech-language outcomes in the meta-analysis for children with ASD (Fuller \& Kaiser, 2020; Hampton \& Kaiser, 2016; Sandbank et al., 2020b). The current synthesis provides an opportunity to test whether a greater amount of time in intervention improves prelinguistic and language outcomes for interventions that use responsivity intervention strategies. As described by Warren et al. (2007), intervention intensity can be quantified in multiple ways. Because we anticipated limited reporting of the necessary details to calculate cumulative intervention intensity, we selected time 
in intervention (minutes per week times number of weeks of intervention) as the intensity variable.

\section{Proximity of Outcome Measure}

Proximal outcome measures assess skills taught directly during the intervention. Distal outcome measures assess skills beyond what was taught directly. As predicted, Yoder et al. (2013) found significantly greater probability of an effect on social communication for proximal outcome measures (63\%) than distal outcome measures (39\%) for children with ASD.

\section{Boundedness of Outcome Measure}

Boundedness of outcome measures refers to the degree to which the occurrence of the outcome behavior depends on the intervention context (e.g., same setting, materials, and/or communication partner; Yoder et al., 2013). Context-bound outcome measures are measured in situations very similar to the treatment sessions (e.g., evaluating the number of intentional communication acts during treatment sessions with the interventionist). In contrast, generalized characteristics are measured in situations that vary from the treatment context in setting, materials, and/or communication partner (e.g., number of intentional communication acts with an unfamiliar clinician during a session in which the intervention strategies are not used). Potentially context-bound outcome measures may show changes that are possibly limited to the treatment context (e.g., standardized caregiver report measure for a caregiver-implemented intervention). Yoder et al. (2013) found greater probability of a significant effect on social communication for context-bound outcome measures $(82 \%)$ than generalized characteristics $(33 \%)$. Boundedness also moderated the mean effect size for the effectiveness of early intervention on social communication skills of children with ASD (Fuller \& Kaiser, 2020).

\section{Risk for Correlated Measurement Error}

Correlated measurement error (CME) systematically elevates the true score for the predicted superior group or phase over the control group or phase (Yoder et al., 2018). Intervention studies are at risk for CME (a) when the outcome measure coder is not blind to treatment assignment and (b) when interventionists (including caregivers) provide the intervention and serve as the examiner when the outcome measure is assessed.

\section{Publication Bias}

Publication bias occurs "when published research on a topic is systematically unrepresentative of the population of completed studies on that topic" (Rothstein, 2008, p. 61). We test for this known risk for meta-analyses by comparing effect sizes of published versus unpublished studies. This examination is a feature of well-designed meta-analyses.

\section{The Current Literature Synthesis}

The purpose of this systematic review and meta-analysis is to describe the current state of the literature for responsivity intervention strategies aimed at improving prelinguistic and language skills of children with ASD with an eventual outcome of shaping the direction of future research studies and clinical practice. Most of the prior reviews are systematic, but do not employ meta-analytic techniques (Mancil et al., 2009; McConachie \& Diggle, 2007; Verschuur et al., 2014). Our review uses meta-analytic techniques to determine the mean effect size not only for group design studies, specifically RCTs, but also for SCRD studies. Including SCRD studies is important because many studies of responsive interventions have used single case designs. SCRD studies avoid the need for large samples required for RCTs to make causal conclusions by each participant serving as their own control and by using specific designs to control for threats to internal validity (Ledford \& Gast, 2018). We restricted the research synthesis to RCTs and SCRD studies because those designs permit causal conclusions, unlike quasi-experimental or other non-randomized group designs. This design requirement combined with the quality analysis enabled this research synthesis to focus on studies with relatively higher quality of evidence. We conducted two separate analyses - one for RCTs and a second for SCRD studies. We then descriptively discuss the results of the two analyses. The review is registered with PROSPERO (CRD42020157374).

\section{Research Questions}

To provide a comprehensive review of the literature, we included RCTs and SCRD studies that met quality criterion. We addressed two primary research questions, separately for the RCT and SCRD studies: (1) Is the mean effect size for interventions that use responsivity intervention strategies on communication and/language skills in children with ASD greater than zero? (2) Does the mean effect size vary by interventionist, time in intervention, proximity or boundedness of the outcome measure, risk for CME, or publication bias? We also assessed study quality descriptively using the Revised Cochrane risk-of-bias tool for randomized trials (RoB 2; Higgins et al., 2019) and What Works Clearinghouse standards 
for SCRDs (What Works Clearinghouse, 2016). Both tools address potential bias from multiple sources including, but not limited to, the study design, completeness of the data, and data analysis.

\section{Methods}

\section{Search Strategy}

Our comprehensive search strategy included multiple search methods. The main search utilized electronic databases. We searched PubMed on October 18, 2019 and the Education Database, ERIC, Health \& Medical Collection, Linguistics and Language Behavior Abstracts, Linguistics Database, ProQuest Dissertations \& Theses Global, Psychology Database, PsycINFO, and Social Science Database in ProQuest and the Cumulative Index of Nursing and Allied Health Literature (CINAHL) on October 19, 2019. See Supplementary Information 1 for an example search.

For supplementary searches, the first author hand searched table of contents for the past year for journals that contributed at least five articles to the full text screening from the main database search (i.e., Autism, Journal of Autism and Developmental Disorders, Journal of Child Psychology and Psychiatry). The first author also screened abstracts from the two prior conferences for the Gatlinburg Conference on Intellectual and Developmental Disabilities, International Meeting for Autism Research, and Society for Research in Child Development to identify findings that may not yet be in publication. Finally, the first author scanned reference lists and conducted forward searches for included studies. The supplementary searches were completed on March 28, 2020.

The primary coder (first author) screened $100 \%$ of the identified reports. Trained research assistants independently screened $25 \%$ of the reports at the title and abstract level and the full text level. The primary coder (first author) was blind to which reports would be coded for reliability. To prevent coder drift, discrepancy discussions were completed regularly. Point-by-point agreement for inclusion or exclusion (i.e., agreements divided by total number of reports) was $89 \%$ at the title and abstract level and $87 \%$ at the full text level. We used the primary coder's decisions for inclusion.

\section{Inclusion Criteria}

\section{Population}

Study participants had to be children diagnosed with ASD with a mean or median age under 18 years, 0 months at intervention initiation. We included numerous diagnostic search terms due to the change in diagnostic criteria and terminology in recent decades. Participants with autism spectrum disorder(s), autism, autistic disorder, pervasive developmental disorder-not otherwise specified, highfunctioning autism, and Asperger's disorder/syndrome were included if they met other inclusion criteria. We only included children at "high-risk" for ASD (e.g., infant siblings of children with ASD) if they were later diagnosed with ASD. For RCTs, each group was required to contain at least five participants to permit calculation of an effect size.

\section{Intervention}

We included studies that tested the effects of a behavioral intervention that used responsivity intervention strategies designed to improve prelinguistic and/or language skills in children with ASD. The interventionist responds to the child's communicative attempts and provides targeted prelinguistic and/or language input. Responsivity intervention strategies include but are not limited to an adult or peer imitating the child's vocalizations or spoken words, recasting the child's verbal or nonverbal communication act, contingent responses to child vocalizations that continues the turn-taking exchange, and follow-in comments. We did not exclude studies based on the type of interventionist (e.g., caregivers, clinicians, teachers, and/or peers).

\section{Comparison}

For RCTs, the treatment group (the group that received responsivity intervention strategies) must be compared with a randomly assigned control group that does not receive responsivity intervention strategies. The control group may vary in type including, but not limited to, other intervention strategies that do not use responsivity intervention strategies, a business-as-usual condition, or a waitlist control. For the SCRD studies, a baseline or alternative intervention condition serves as the comparison, depending on the study design.

\section{Outcomes}

Studies must report at least one prelinguistic skill and/or language measure for the child participants with ASD. Outcome measures may be expressive language (e.g., expressive vocabulary, mean length of utterance, and requests), receptive language (e.g., receptive vocabulary and following directions), or prelinguistic skills (e.g., directed vocalizations, joint attention, and gestures).

For the RCTs, each report must include at least one group mean difference effect size or sufficient data to calculate 
one for an eligible outcome measure. For applicable SCRD studies, we calculated the between-case standardized mean difference (BC-SMD) because it applies to multiple baseline across participants studies (the most common design of this review), quantifies magnitude and consistency of change, and is more similar to group design effect sizes than withincase effect sizes (Hedges et al., 2012, 2013; Pustejovsky et al., 2014; Valentine et al., 2016). We present the RCT and SCRD study results separately to permit comparison of the RCT results with prior meta-analyses and to avoid differences in weighting of sample sizes across study types (Valentine et al., 2016).

\section{Exclusion Criteria}

To maintain an appropriately narrow focus, literacy, vocal stereotypy, and challenging behavior outcomes were excluded. We also excluded outcome measures that focused on the interventionist's performance (e.g., number of adult conversational turns, prompts to the child, or use of intervention strategies). We excluded studies not written in English due to lack of translation resources. Studies were not excluded based on the language of the participants or the publication date. At the final stage of the full text screening, we excluded SCRD studies that failed to meet quality standards from the qualitative and quantitative analyses because failing to meet those standards prevents interpretation of the findings (What Works Clearinghouse, 2016). Broadly, the following criteria must be met to demonstrate an intervention effect: (a) graphical display of the data, (b) at least three attempts to demonstrate an effect and (c) a sufficient number of data points per phase (e.g., at least three data points per phase to meet with reservations and at least five data points per phase to meet without reservations for multiple baseline, multiple probe, and ABAB [reversal/withdrawal] designs; What Works Clearinghouse, 2016). Multiple baseline and multiple probe designs must also have sufficiently overlapping baselines across tiers. Failure to meet all these criteria resulted in exclusion from the qualitative and quantitative analyses. For additional details, refer to the What Works Clearinghouse Study Review Guide Instructions for Reviewing Single-Case Designs Studies (What Works Clearinghouse, 2016).

\section{Study Selection}

As shown in the Preferred Reporting Items for Systematic Reviews and Meta-Analyses (PRISMA) flow diagram (Fig. 1), database searches yielded 7108 records and other sources yielded 149 records. After eliminating duplicates and screening the titles and abstracts, 770 records remained. During the full text screening, independent coders eliminated studies in the order listed in Fig. 1. For the SCRD studies, the final inclusion criterion was meeting quality standards with or without reservations. The search yielded 33 RCTs that were described in 45 reports and included 294 relevant effect sizes and 42 SCRD studies that were described in 47 reports. Thirty-seven SCRD studies included sufficient graphical information for visual analysis (91 relevant opportunities to detect a functional relation) and 34 permitted extractions of at least one BC-SMD effect size (69 total BC-SMD effect sizes).

\section{Coding the Studies}

All reports were coded by the primary coder (first author) and trained research assistants using a detailed coding manual (available from first author upon request). For the RCTs, point-by-point agreement for data extraction and bias coding was $94 \%$ and $90 \%$, respectively. For the SCRD studies, point-by-point agreement for quality coding, data extraction, and visual analysis was $80 \%, 92 \%$, and $80 \%$ respectively. Discrepancies were resolved by consensus. Consensus coding was used for all analyses.

Report level features included publication status, report type, country, spoken language of the participants, and percent of participants who are monolingual. Effect size level features included sample size (for ASD group and control group for RCTs), sex, age, intervention, interventionist, time in intervention, outcome measure(s), and effect size. The total time in intervention is the number of minutes per week multiplied by the number of weeks of intervention. For caregiver-implemented interventions, the amount of time is based on structured intervention time, not all waking hours, even though a caregiver may implement at least some strategies throughout the entire day. We categorized the outcome measures as distal or proximal and context-bound, potentially context-bound, or a generalized characteristic.

For risk of bias for RCTs, we used the Revised Cochrane risk-of-bias tool for randomized trials (RoB 2; Higgins et al., 2019). We rated each study for low, moderate, or high risk of bias for randomization process, deviations from intended interventions, missing outcome data, measurement of outcome, selection of reported result, and overall. In addition, coded study quality features include risk for CME, method of handling missing data, and use of blind assessors. For quality coding for the SCRD studies we used guidelines provided by the What Works Clearinghouse Study Review Guide Instructions for Reviewing Single-Case Designs Studies (What Works Clearinghouse, 2016). Studies that did not meet quality standards with or without reservations were excluded from the meta-analysis. Remaining studies were categorized as meeting standards with versus without reservations. 


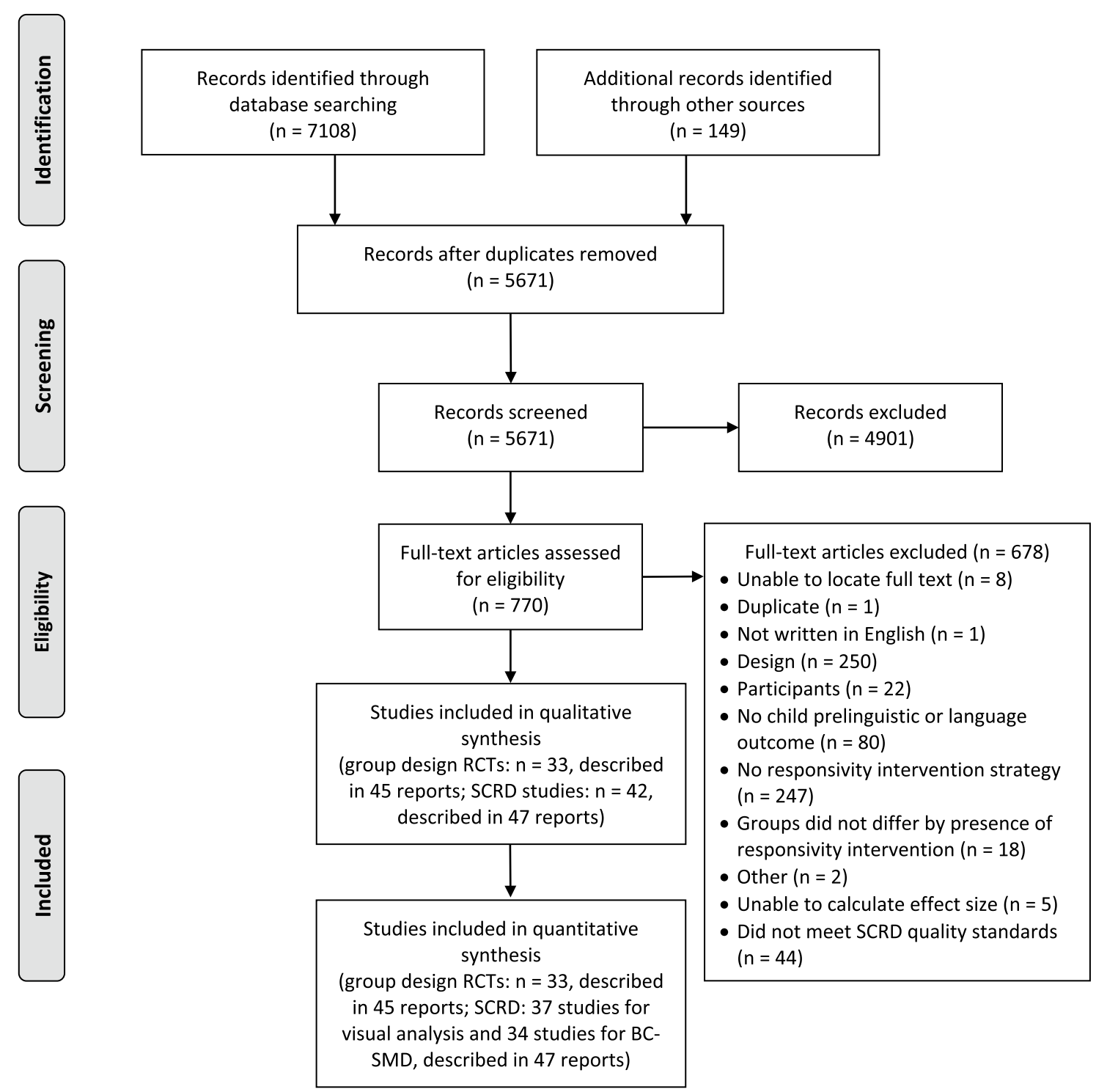

Fig. 1 Preferred Reporting Items for Systematic Reviews and Meta-Analyses (PRISMA) flow diagram. BC-SMD=between-case standardized mean difference; $\mathrm{RCTs}=$ randomized controlled trials; $\mathrm{SCRD}=$ single case research design

\section{Analytic Strategies}

\section{Effect Size}

For the RCTs, we calculated the standardized mean difference $(d)$ for independent groups (i.e., mean of responsivity intervention group minus the mean of the control group divided by the within-groups standard deviation) for each relevant outcome measure (Borenstein et al., 2009). Consistent with current meta-analytic techniques, we then used a correction factor to convert to Hedges' $g$ to address the tendency for $d$ to overestimate the standardized mean difference for small samples (Borenstein et al., 2009).
For the SCRD studies, we digitized the data (Huwaldt, 2010) to convert the graphical data into numerical data. We then calculated the BC-SMD using the online singlecase design hierarchical linear model (scdhlm) web application (Valentine et al., 2016). For consistency, all effect sizes were calculated with restricted maximum likelihood estimation and with fixed and random effects permitted for the baseline and intervention phases (Valentine et al., 2016). 


\section{Visual Analysis for SCRD Studies}

For visual analysis for SCRDs, we followed guidelines by Kratochwill et al. (2010), What Works Clearinghouse Single-Case Design Technical Documentation, for determining whether an effect is present. The visual analysis focuses on level, trend, variability, immediacy of the effect, overlap, and consistency of data patterns across similar phases.

\section{Robust Variance Estimation}

Because traditional meta-analytic techniques assume that all effect sizes are independent, only one effect size per sample can be used. In contrast, robust variance estimation permits inclusion of multiple effect sizes per study (Hedges et al., 2010; Tanner-Smith \& Tipton, 2014). We used a random effects model with approximately inverse variance weights to address the dependency of multiple effect sizes per study via the robumeta.ado file from the Stata Statistical Software Components archive.

\section{Moderator Analyses for Putative Moderators of Intervention Effects}

We used meta-regression with robust variation estimation to conduct the planned moderator analyses. To evaluate variation in effectiveness across studies that use responsivity intervention strategies, we tested six moderators as shown in Table 1. After examining intercorrelations among putative moderators, all moderators were tested independently.

\section{Results}

\section{Study Characteristics}

For the RCTs, Tables 2 and 3 display participant characteristics and intervention features. At least 897 unique participants (accounting for possible overlap between studies) are included in at least one effect size. Participants' mean age at study initiation was 43.01 months ( $S D=17.97$ months). A variety of interventions were implemented. Joint attention intervention / JASPER (8 studies) and PRT (6 studies) were

Table 1 Putative moderators of intervention effect by type

\begin{tabular}{lll}
\hline Intervention implementation & $\begin{array}{l}\text { Type of out- } \\
\text { come measure }\end{array}$ & Study quality \\
\hline Interventionist & Boundedness & $\begin{array}{l}\text { Publication bias } \\
\text { Time in intervention }\end{array}$ \\
& Proximity & $\begin{array}{l}\text { Risk for correlated } \\
\text { measurement } \\
\text { error }\end{array}$ \\
& & \\
\hline
\end{tabular}

most common. JASPER targets joint attention, play, and imitation through a combination of behavioral and developmental principles (Chang et al., 2016; Goods et al., 2013; Kasari et al., 2006). PRT is designed to target "pivotal" areas using ABA principles and to train caregivers in the strategies to do so (Hardan et al., 2015). Caregivers were the most common interventionist (17 studies). Table 4 displays details for effect size features, including outcome measures. The included studies used a wide variety of outcome measures and varied in the number of effect sizes per study, ranging from 1 to 78 .

For the SCRD studies, Tables 5 and 6 display participant characteristics and intervention features. The studies included at least 143 unique participants with an average of 3.40 participants per study $(S D=1.17)$. Only participants who contributed data included for visual analysis or an effect size were included. The mean age of participants prior to intervention was 54.36 months $(S D=25.72)$. Table 7 displays effect size features (e.g., outcome measures and results) and visual analysis results.

\section{Quality Indicators}

For the RCTs, overall risk of bias was judged to be high for 25 studies, moderate for 7 studies, and low for only 1 study. It should be noted that a "high" risk of bias rating for any category results in an overall risk of bias rating of "high". See Tables 8 and 9 for details. Many studies were noted to be at risk for CME which resulted in high risk of bias for "Measurement of outcome." Only seven of the RCTs provided sufficient information to determine whether there were deviations from the intended intervention (a component of "Deviations from intended interventions"). Of those, three indicated probable risk of bias. Studies were judged to deviate from the intended intervention if the mean or median procedural fidelity value was below $80 \%$. "Sufficient information" required that procedural fidelity data to be drawn from at least $20 \%$ of sessions or participants. Similar gaps in reporting of outcome measure reliability were also observed, as shown in Table 9. The high number of studies without sufficient information about procedural fidelity and reliability reveals an area of need for improving the quality of available studies. It inhibits quantitative analysis of the influence of procedural fidelity and reliability on intervention effects. No studies were at high risk of bias for the randomization process and only three were at high risk for deviations from the intended interventions.

For the SCRD studies, only three studies included at least one distal outcome measure (Carpenter, 2003; Ingersoll \& Wainer, 2003, 2013). All outcome measures were context-bound and at risk for CME. The high proportion of proximal and context-bound outcome measures is consistent with Yoder et al. (2013). For study quality, 25 of the 47 
Table 2 Participant characteristics for included randomized controlled trials

\begin{tabular}{|c|c|c|c|c|c|c|}
\hline Reference & Pub & Loc & $n$ & T1 $M$ age (mths) & T1 Developmental Level $M(S D)$ & ASD Severity $M(S D)$ \\
\hline \multicolumn{7}{|l|}{ Independent samples } \\
\hline Boyd et al., (2018) & Yes & USA & 82 & 49 & $\begin{array}{l}\text { MSEL composite SS: } 54.03 \\
(11.31)\end{array}$ & ADOS severity: 7.10 (1.91) \\
\hline Carter et al., (2011) & Yes & USA & 28 & 21 & MSEL EL AE: 8.22 (6.01) & NR \\
\hline Chang et al., (2016) & Yes & USA* & 38 & 49 & MSEL MA: 34.52 (10.73) & ADOS severity: 7.06 (1.26) \\
\hline $\begin{array}{l}\text { Clionsky, (2012) \& Ginn et al., } \\
\text { (2017) }\end{array}$ & Mixed & USA & 15 & 57 & NR & CARS-II severity: 49.67 (7.16) \\
\hline Drew et al., (2002) & Yes & UK & 12 & 21 & GSMD NVIQ: 88.1 (11.2) & ADI RSI: 19.6 (3.0) \\
\hline Gengoux et al., (2019) & Yes & USA & 23 & 50 & MSEL composite SS: 49.9 & CGI-S: $5.4(0.5)$ \\
\hline Goods et al., (2013) & Yes & USA* & 5 & 49 & MSEL DQ: 37.70 (15.21) & NR \\
\hline Hardan et al., (2015) & Yes & USA $*$ & 25 & 49 & MSEL DQ: 52.8 (16.4) & CGI-S: $5.2(0.9)$ \\
\hline Kaale et al., (2012) & Yes & Norway & 34 & 48 & MSEL DQ: 53.3 (19.2) & NR \\
\hline Kasari et al., (2010) & Yes & USA* & 19 & 30 & MSEL DQ: 64.80 (5.35) & $\mathrm{NR}$ \\
\hline Kasari et al., (2014) & Yes & USA & 51 & 42 & MSEL MA: 23.6 (11.6) & ADOS severity: 7.23 (1.6) \\
\hline Kasari et al., (2015) & Yes & USA* & 43 & 31 & MSEL DQ: 68.0 (20.3) & NR \\
\hline Landa et al., (2011) & Yes & USA & 24 & 29 & MSEL VR T-score: 27.50 (8.27) & NR \\
\hline Lawton \& Kasari, (2012b) & Yes & USA & 9 & 46 & MSEL MA: 30.3 (5.01) & NR \\
\hline $\begin{array}{l}\text { Mohammadzaheri et al., } \\
\text { (2014) }\end{array}$ & Yes & Iran & 15 & 111 & Summary score NR & NR \\
\hline Nefdt et al., (2010) & Yes & USA* & 13 & 39 & NR & NR \\
\hline Openden, (2005) & No & USA & 16 & 58 & NR & NR \\
\hline Rahman et al., (2016) & Yes & India \& Pakistan & 29 & 64 & VABS AB SS: 62.53 (12.15) & NR \\
\hline Schertz et al., (2013) & Yes & USA & 11 & 25 & NR & NR \\
\hline Schertz et al., (2018) & Yes & USA & 64 & 25 & $\begin{array}{l}\text { MSEL composite SS: } 104.48 \\
(35.16)\end{array}$ & ADOS-T severity: 16.36 (3.45) \\
\hline Schreibman \& Stahmer, (2014) & Yes & USA* & 20 & 30 & Summary score NR & NR \\
\hline Siller et al., (2013) & Yes & USA & 34 & 58 & MSEL VR AE: 26.6 (9.4) & $\begin{array}{l}\text { ADOS Social Affect: } 14.7 \\
(3.3)\end{array}$ \\
\hline Turner-Brown et al., (2019) & Yes & USA & 32 & 30 & $\begin{array}{l}\text { MSEL composite SS: } 62.53 \\
\quad(16.12)\end{array}$ & PIA total: $2.82(0.61)$ \\
\hline Venker et al., (2012) & Yes & USA* & 7 & $41^{\dagger}$ & MSEL VR AE: $28.79(13.80)^{\dagger}$ & ADOS severity: $8(2.13)^{\dagger}$ \\
\hline Vernon et al., (2019) & Yes & USA* & 12 & 38 & $\begin{array}{l}\text { MSEL composite SS: } 76.08 \\
\text { (20.38) }\end{array}$ & ADOS severity: 7.00 (1.48) \\
\hline Warreyn \& Roeyers, (2014) & Yes & Belgium & 18 & 69 & PIQ: 79.38 (16.19) & NR \\
\hline Wong, (2013) & Yes & USA* & 18 & NR & NR & NR \\
\hline \multicolumn{7}{|l|}{ Shared samples } \\
\hline Aldred et al., (2004) sample & Yes & England & 14 & $48-51$ & VABS AB composite: 25.6 (9.2) & $\begin{array}{l}\text { ADI median: 16.5; range } \\
\text { 11-21 }\end{array}$ \\
\hline Dawson et al., (2010) sample & Mixed & USA & $15-24$ & 24 & MSEL NVIQ: 83.6 (13.3) & ADOS severity: 7.2 (1.7) \\
\hline Green et al., (2010) sample & Yes & UK & $74-77$ & 45 & MSEL NVIQ AE: 27.0 (10.0) & ADOS severity: 8.0 (1.4) \\
\hline Kasari et al., (2006) sample & Yes & USA & $15-20$ & $42-43$ & MSEL DQ: 58.30 (17.18) & NR \\
\hline Ingersoll, (2010) sample & Yes & USA* & $11-14$ & $39-41$ & Bayley NV MA: 20.8 (6.6) & NR \\
\hline Rogers et al., (2012) sample & Yes & USA & $49-51$ & 21 & MSEL DQ: 66.89 (18.61) & ADOS severity: 7.20 (1.94) \\
\hline
\end{tabular}

*Location based on the first author because it was not stated explicitly

†alue includes control group because not reported for only treatment group

$A B$ adaptive behavior, ADI Autism Diagnostic Interview (Lord et al., 1994), ADOS Autism Diagnostic Observation Schedule (Lord et al., 1999), AE age equivalent, ASD autism spectrum disorder, Bayley Bayley Scales of Infant \& Toddler Development (Bayley, 2005), CARS-II Childhood Autism Rating Scale (Second Edition; Schopler et al., 2010), CGI-S Clinical Global Impressions Scale - Severity (Guy, 1976), DQ developmental quotient, EL expressive language, GSMD Griffiths Scale of Mental Development—D and E scales (Griffiths, 1986), Loc location, $M$ mean, $M A$ mental age, MSEL Mullen Scales of Early Learning (Mullen, 1995), $m$ ths months, $N R$ not reported, $N V$ nonverbal, $N V I Q$ nonverbal intelligence quotient, PIA Parent Interview for Autism-Clinical Version (Stone et al., 2003), PIQ performance intelligence quotient, Pub published, RSI Reciprocal Social Interaction, SS standard score, $T 1$ Time 1 / prior to intervention, UK United Kingdom, USA United States of America, VABS Vineland Adaptive Behavior Scales (Sparrow et al., 1984), VR Visual Reception

included reports met quality standards without reservations.

As shown in Fig. 1, 44 reports that otherwise would have 


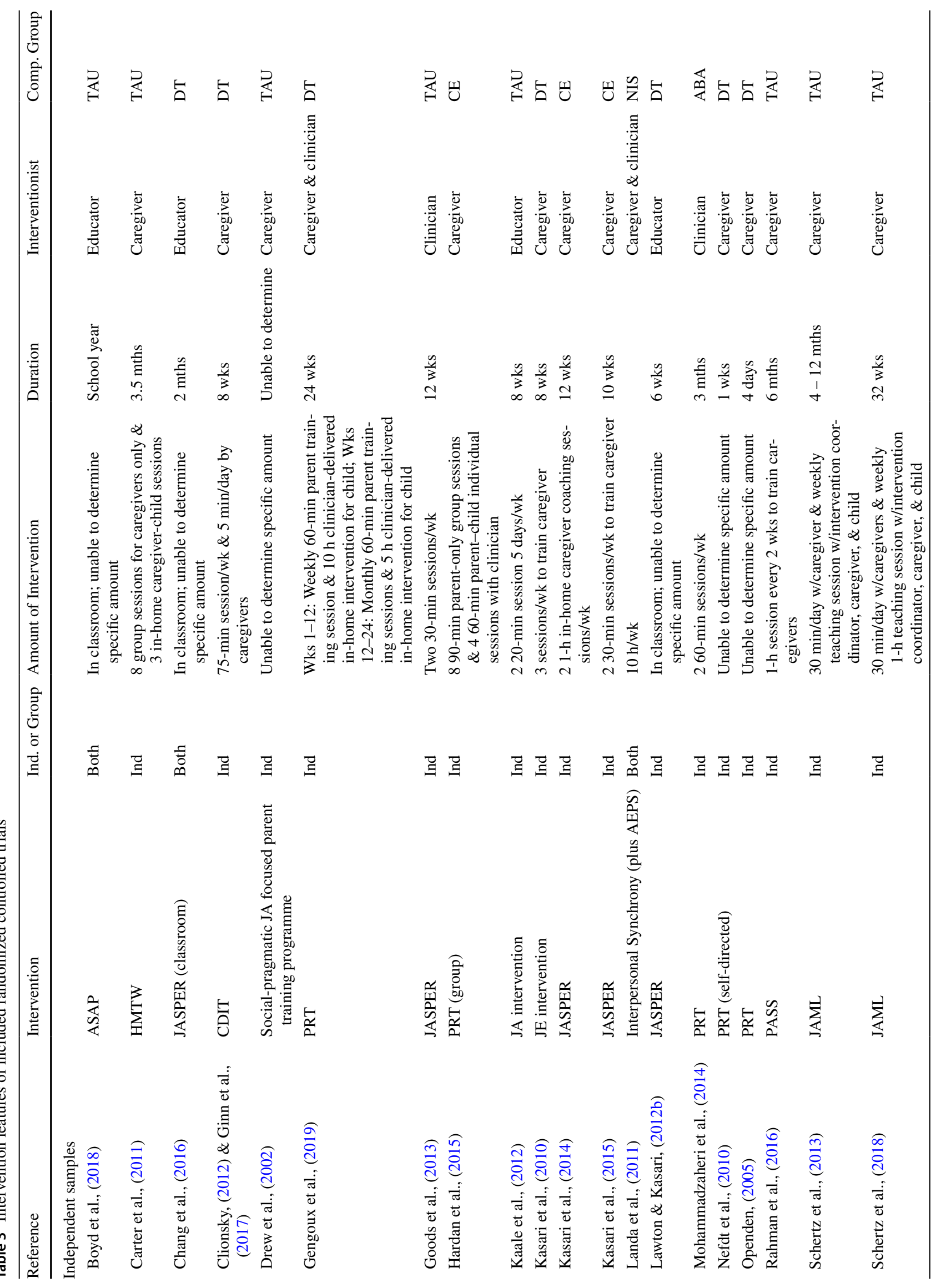




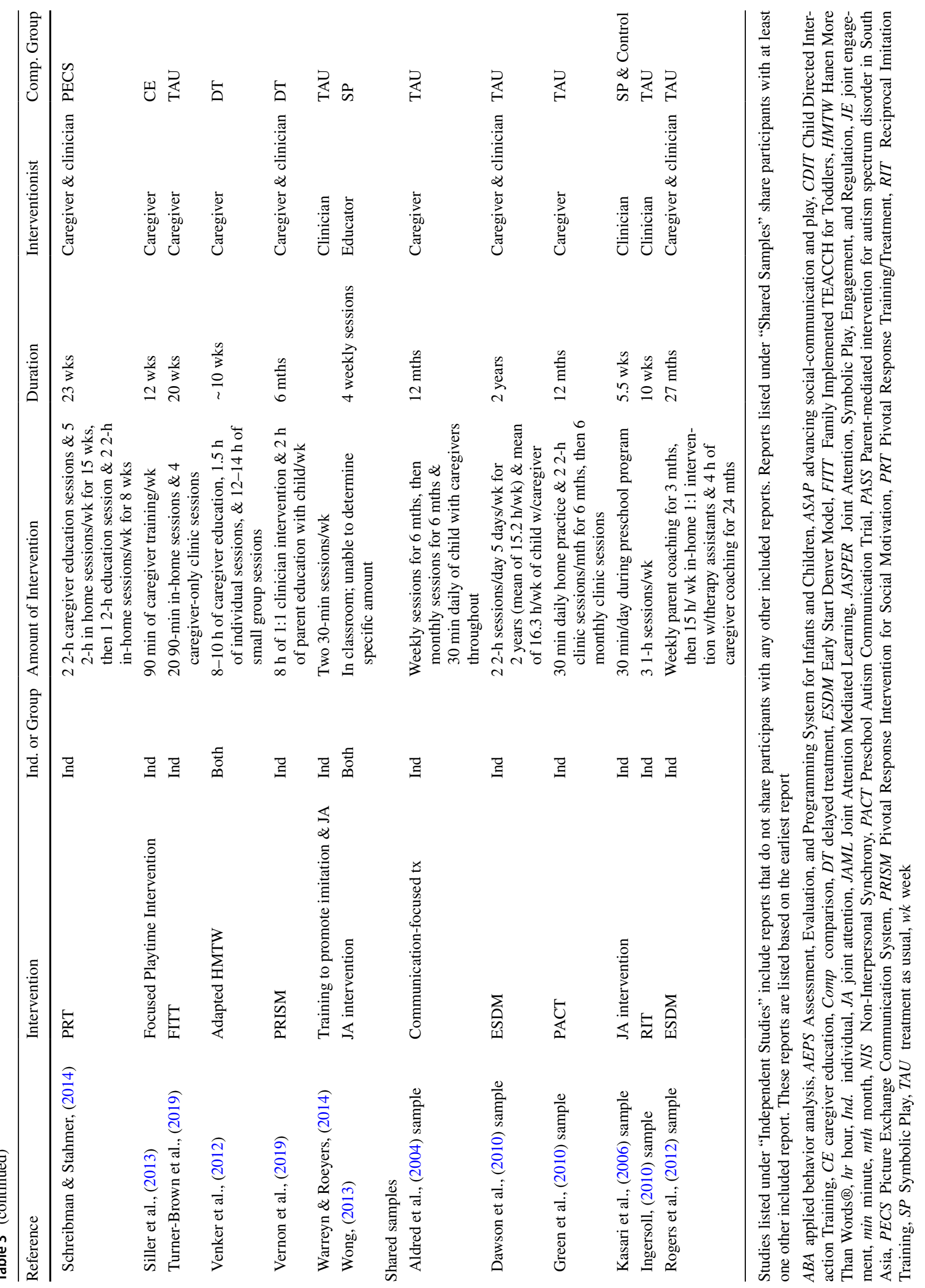


Table 4 Effect size characteristics and outcome measures for included randomized controlled trials

\begin{tabular}{|c|c|c|c|c|c|c|}
\hline & $n$ & Prox./Dis & $\begin{array}{l}\mathrm{CB} / \\
\mathrm{PCB} / \\
\mathrm{GC}\end{array}$ & $\begin{array}{l}\text { CME } \\
\text { Risk }\end{array}$ & $\begin{array}{l}\text { Mean } \\
E S\end{array}$ & Outcome Measure(s) \\
\hline \multicolumn{7}{|l|}{ Independent samples } \\
\hline Boyd et al., (2018) & 82 & $8 / 0$ & $0 / 0 / 8$ & 0 & -0.09 & $\begin{array}{l}\text { Observational coding of JA, requesting, and social interaction dur- } \\
\text { ing ADOS }\end{array}$ \\
\hline Carter et al., (2011) & 28 & $6 / 6$ & $2 / 3 / 7$ & 5 & -0.07 & $\begin{array}{l}\text { ESCS for initiating JA and BR; MSEL Receptive and Expressive } \\
\text { Communication; PIA Nonverbal Communication; PCFP weighted } \\
\text { frequency of intentional communication; VABS Communication }\end{array}$ \\
\hline Chang et al., (2016) & 38 & $10 / 0$ & $8 / 0 / 2$ & 8 & 0.40 & $\mathrm{JA}$ and BR during play session \\
\hline $\begin{array}{l}\text { Clionsky, (2012) \& Ginn } \\
\text { et al., (2017) }\end{array}$ & 15 & $0 / 4$ & $2 / 1 / 1$ & 3 & -0.25 & $\begin{array}{l}\text { Child word count; PPVT-3; SRS Communication; total child ver- } \\
\text { balizations }\end{array}$ \\
\hline Drew et al., (2002) & 12 & $0 / 6$ & $0 / 6 / 0$ & 6 & 0.61 & $\begin{array}{l}\text { ADI RSI and Nonverbal Communication; ADOS Improved Spoken } \\
\text { Language Classification; MCDI words understood, words said, } \\
\text { and total gestures }\end{array}$ \\
\hline Gengoux et al., (2019) & 23 & $5 / 12$ & $6 / 7 / 4$ & 13 & 0.56 & $\begin{array}{l}\text { BOSCC Social Communication; CGI-Improvement; CGI-Severity; } \\
\text { MCDI words produced; MSEL Expressive Language; PLS-5 } \\
\text { Expressive Language; SLO imitative, prompted (verbally and non- } \\
\text { verbally), spontaneous utterances; SRS-2 Social Communication; } \\
\text { VABS Communication and Expressive Language }\end{array}$ \\
\hline Goods et al., (2013) & 5 & $4 / 2$ & $2 / 0 / 4$ & 0 & 0.51 & $\begin{array}{l}\text { Initiating JA and BR during ESCS and classroom observation; } \\
\text { RDLS Verbal Communication and Expressive Language }\end{array}$ \\
\hline Hardan et al., (2015) & 25 & $5 / 9$ & $5 / 8 / 1$ & 13 & 0.39 & $\begin{array}{l}\text { CGI-Improvement; CGI-Severity; MCDI MLU and words said; PLS } \\
\text { Expressive Communication; SLO imitative, prompted (verbally } \\
\text { and nonverbally), and spontaneous utterances; VABS Communi- } \\
\text { cation, Expressive Language, and Receptive Language }\end{array}$ \\
\hline Kaale et al., (2012) & 34 & $3 / 0$ & $1 / 1 / 1$ & 2 & 0.25 & $\begin{array}{l}\text { Child-initiated higher order JA during ESCS, mother-child play, } \\
\text { and teacher-child play }\end{array}$ \\
\hline Kasari et al., (2010) & 19 & $2 / 0$ & $2 / 0 / 0$ & 2 & 1.48 & Initiating and responding to JA during caregiver-child interaction \\
\hline Kasari et al., (2014) & 51 & $2 / 0$ & $0 / 0 / 2$ & 0 & -0.14 & ESCS Initiating JA \\
\hline Kasari et al., (2015) & 43 & $2 / 4$ & $0 / 2 / 4$ & 2 & 0.00 & $\begin{array}{l}\text { Initiating JA during parent-child interaction; RDLS Expressive } \\
\text { Language and Receptive Language }\end{array}$ \\
\hline Landa et al., (2011) & 24 & $2 / 2$ & $0 / 0 / 4$ & 4 & 0.29 & Initiating JA during CSBS; MSEL Expressive Language \\
\hline Lawton \& Kasari, (2012b) & 9 & $15 / 0$ & $10 / 0 / 5$ & 10 & 0.67 & $\begin{array}{l}\text { Pointing, showing, giving, and looking during classroom observa- } \\
\text { tion, ESCS, and play interaction }\end{array}$ \\
\hline $\begin{array}{l}\text { Mohammadzaheri et al., } \\
\text { (2014) }\end{array}$ & 15 & $0 / 2$ & $0 / 0 / 2$ & 2 & 1.29 & $\mathrm{CCC}$ and $\mathrm{MLU}$ \\
\hline Nefdt et al., (2010) & 13 & $1 / 0$ & $1 / 0 / 0$ & 1 & 0.89 & Functional verbal utterances \\
\hline Openden, (2005) & 16 & $2 / 0$ & $2 / 0 / 0$ & 2 & 0.25 & $\begin{array}{l}\text { Functional verbal utterances and responsivity to opportunities for } \\
\text { language }\end{array}$ \\
\hline Rahman et al., (2016) & 29 & $2 / 5$ & $2 / 5 / 0$ & 7 & -0.06 & $\begin{array}{l}\text { CSBS Social Composite and total weighted raw score; initiating } \\
\text { communication acts; MCDI Expressive Language and Receptive } \\
\text { Language; mutual shared attention; VABS Communication }\end{array}$ \\
\hline Schertz et al., (2013) & 11 & $4 / 3$ & $4 / 1 / 2$ & 5 & 0.78 & $\begin{array}{l}\text { MSEL Expressive Language and Receptive Language; PJAM initi- } \\
\text { ating and responding to JA; VABS Communication }\end{array}$ \\
\hline Schertz et al., (2018) & 64 & $4 / 0$ & $4 / 0 / 0$ & 4 & 0.57 & PJAM initiating and responding to JA \\
\hline $\begin{array}{l}\text { Schreibman \& Stahmer, } \\
\text { (2014) }\end{array}$ & 20 & $0 / 6$ & $0 / 4 / 2$ & 4 & -0.33 & $\begin{array}{l}\text { MCDI words said; MSEL Expressive Language; VABS Communi- } \\
\text { cation }\end{array}$ \\
\hline Siller et al., (2013) & 34 & $0 / 2$ & $0 / 0 / 2$ & 0 & 0.97 & MSEL Expressive Language \\
\hline Turner-Brown et al., (2019) & 32 & $0 / 3$ & $0 / 2 / 1$ & 2 & -0.19 & $\begin{array}{l}\text { MSEL Expressive Language; PIA Nonverbal Communication and } \\
\text { Understanding }\end{array}$ \\
\hline Venker et al., (2012) & 7 & $3 / 0$ & $3 / 0 / 0$ & 3 & 0.11 & $\begin{array}{l}\text { Prompted, spontaneous verbal, and spontaneous nonverbal com- } \\
\text { munication }\end{array}$ \\
\hline Vernon et al., (2019) & 12 & $0 / 9$ & $0 / 1 / 8$ & 9 & 0.87 & $\begin{array}{l}\text { EVT-2; MSEL Early Learning Composite, Expressive Language, } \\
\text { and Receptive Language; PLS-5 Auditory Comprehension, } \\
\text { Expressive Communication and Total Language; PPVT-4; VABS } \\
\text { Communication }\end{array}$ \\
\hline
\end{tabular}


Table 4 (continued)

\begin{tabular}{|c|c|c|c|c|c|c|}
\hline & $n$ & Prox./Dis & $\begin{array}{l}\mathrm{CB} / \\
\mathrm{PCB} / \\
\mathrm{GC}\end{array}$ & $\begin{array}{l}\text { CME } \\
\text { Risk }\end{array}$ & $\begin{array}{l}\text { Mean } \\
E S\end{array}$ & Outcome Measure(s) \\
\hline Warreyn \& Roeyers, (2014) & 18 & $9 / 0$ & $0 / 0 / 9$ & 9 & 0.50 & $\begin{array}{l}\text { Imitation (gestural, verbal, and symbolic) and JA (gaze following, } \\
\text { initiating and responding to declarative JA, initiating requests, and } \\
\text { reactions to ambiguous behavior) during examiner-child interac- } \\
\text { tion }\end{array}$ \\
\hline Wong, (2013) & 18 & $2 / 0$ & $2 / 0 / 0$ & 2 & 0.41 & Initiating and responding to JA during classroom observation \\
\hline \multicolumn{7}{|l|}{ Shared Samples } \\
\hline \multicolumn{7}{|c|}{ From Aldred et al., (2004) sample } \\
\hline Aldred et al., (2004) & 14 & $2 / 4$ & $2 / 1 / 3$ & 3 & 0.42 & $\begin{array}{l}\text { ADOS Reciprocal Social Interaction; child communication acts; } \\
\text { child shared attention; MCDI words said and words understood; } \\
\text { VABS Communication }\end{array}$ \\
\hline Aldred et al., (2012) & 14 & $0 / 1$ & $0 / 0 / 1$ & 0 & 0.76 & ADOS Social Communication \\
\hline \multicolumn{7}{|c|}{ From Dawson et al., 2010 sample } \\
\hline Dawson et al., (2010) & 24 & $0 / 4$ & $0 / 2 / 2$ & 2 & 0.41 & $\begin{array}{l}\text { MSEL Expressive Language and Receptive Language; VABS Com- } \\
\text { munication }\end{array}$ \\
\hline Dawson et al., (2012) & 15 & $0 / 3$ & $0 / 3 / 0$ & 3 & 1.16 & $\begin{array}{l}\text { PDD-BI Expressive Social Communication, Receptive/Expression } \\
\text { Social Communication, and Expressive Language }\end{array}$ \\
\hline Sullivan, (2014) & 24 & $0 / 5$ & $0 / 0 / 5$ & 1 & 0.37 & MSEL Expressive Language and Receptive Language \\
\hline Estes et al., (2015) & 17 & $0 / 1$ & $0 / 1 / 0$ & 1 & 0.44 & VABS Communication \\
\hline \multicolumn{7}{|c|}{ From Green et al., (2010) sample } \\
\hline Green et al., (2010) & 74 & $2 / 8$ & $2 / 3 / 5$ & 5 & 0.15 & $\begin{array}{l}\text { ADOS-G Communication and Social Communication; child imita- } \\
\text { tions and shared attention during parent-child interaction; CSBS; } \\
\text { MCDI words said and words understood; PLS Auditory Compre- } \\
\text { hension and Expressive Communication; VABS Communication }\end{array}$ \\
\hline Pickles et al., (2016) & 77 & $4 / 2$ & $4 / 1 / 1$ & 5 & 0.27 & CELF-4; child communication initiations; conversation turns; SCQ \\
\hline \multicolumn{7}{|c|}{ From Kasari et al., (2006) sample } \\
\hline Kasari et al., (2006) & 20 & $22 / 0$ & $0 / 0 / 22$ & 0 & 0.26 & $\begin{array}{l}\text { Initiating and responding to JA during ESCS and mother-child } \\
\text { interaction }\end{array}$ \\
\hline Gulsrud et al., (2007) & 17 & $4 / 2$ & $6 / 0 / 0$ & 6 & 0.02 & Verbalizations; non-verbal gestures \\
\hline Kasari et al., (2008) & 20 & $24 / 12$ & $0 / 0 / 36$ & 0 & 0.16 & $\begin{array}{l}\text { Initiating responding to JA during ESCS and mother-child interac- } \\
\text { tion; RDLS Expressive Language and Receptive Language }\end{array}$ \\
\hline Kasari et al., (2012) & 15 & $0 / 2$ & $0 / 0 / 2$ & 0 & 0.15 & EVT \\
\hline Lawton \& Kasari, (2012a) & 20 & $12 / 0$ & $0 / 0 / 12$ & 0 & 0.14 & JA, shared positive affect, and utterances \\
\hline \multicolumn{7}{|c|}{ From Ingersoll, (2010) sample } \\
\hline Ingersoll, (2010) & 11 & $1 / 0$ & $0 / 0 / 1$ & 0 & 1.38 & Gesture imitation \\
\hline Ingersoll, (2012) & 14 & $0 / 1$ & $0 / 0 / 1$ & 0 & 0.83 & ESCS initiating JA \\
\hline \multicolumn{7}{|c|}{ From Rogers et al., (2012) sample } \\
\hline Rogers et al., (2012) & 49 & $1 / 5$ & $0 / 5 / 1$ & 5 & -0.11 & $\begin{array}{l}\text { JA; MCDI phrases understood, total gestures, words said, and words } \\
\text { understood; VABS Communication }\end{array}$ \\
\hline Rogers et al., (2019) & 51 & $3 / 3$ & $0 / 0 / 6$ & 0 & 0.12 & JA; MSEL Expressive Language and Receptive Language \\
\hline
\end{tabular}

ADI Autism Diagnostic Interview (Lord et al., 1994), ADOS Autism Diagnostic Observation Schedule (Lord et al., 1999), BOSCC Brief Observation of Social Communication Change (Grzadzinski et al., 2016), BR behavior regulation, $C B$ context-bound, $C C C$ Children's Communication Checklist (Bishop, 2006), CELF Clinical Foundations of Language Fundamentals (Semel et al., 2006), CGI Clinical Global Impressions Scale (Guy, 1976), CME correlated measurement error, CSBS Communication and Symbolic Behaviors Scale (Wetherby \& Prizant, 2002), Dis. distal, ES effect size, ESCS Early Social Communication Scales (Mundy et al., 2003), EVT-2 Expressive Vocabulary Test - Second Edition (Williams, 2007), GC generalized characteristic, JA joint attention, MCDI MacArthur Communicative Development Inventory (Fenson et al., 1993), $M L U$ mean length of utterance, MSEL Mullen Scales of Early Learning (Mullen, 1995), PCB Potentially context-bound, PCFP parent-child free play, PDD-BI Pervasive Developmental Disorder - Behavior Inventory (Cohen et al., 2003), PIA Parent Interview for AutismClinical Version (Stone et al., 2003), PJAM Precursors of Joint Attention Measure (Schertz, 2005), PLS Preschool Language Scale (Zimmerman et al., 2011), PPVT Peabody Picture Vocabulary Test (Dunn \& Dunn, 1997), Prox. proximal, RDLS Reynell Developmental Language Scales (Reynell \& Curwen, 1977), RSI Reciprocal Social Interaction, SCQ Social Communication Questionnaire (Rutter et al., 2003), SLO structured laboratory observation, SRS Social Responsiveness Scale (Constantino \& Gruber, 2005), SRS-2 Social Responsiveness Scale-Second Edition (Constantino, 2012), VABS Vineland Adaptive Behavior Scales (Sparrow et al., 2005) 
been included were excluded due to failing to meet quality standards (listed in Supplementary Information 2). Twentythree SCRDs provided some type of summary value for procedural fidelity of the interventionist (see Table 10). Nine additional SCRD studies provided fidelity data for the interventionists, but not in a summative form (e.g., graphically or narrative description). However, only two studies (Randolph et al., 2011; Vogler-Elias, 2009) reported procedural fidelity data for the trainers (e.g., a trainer who taught a caregiver to implement the intervention). The ten remaining SCRD studies did not report procedural fidelity data. Similar to the RCTs, the gaps in reporting of procedural fidelity reveal an area of need for improving the quality of available studies. Relative to procedural fidelity data, the SCRD studies more consistently reported interobserver agreement (IOA) data for the outcome measure. Only one study omitted IOA data, revealing an area of strength for the included studies.

\section{Effect Size}

We reject the null hypothesis that there is no effect of interventions using responsivity strategies on prelinguistic and language skills of children with ASD for the RCTs and SCRD studies (research question 1). For the RCTs, the mean standardized group difference is $g=0.36,95 \%$ CI [0.21, $0.51]$, which is a moderate effect size. No variation in the weighted mean effect sizes were observed when we varied the $p$ value in Stata at 0.1 increments from 0.0 to 0.9.

For the SCRD studies, the mean BC-SMD $=1.20,95 \%$ CI $[0.87,1.54]$, which is large. No variation in the weighted mean effect sizes were observed when we varied the $p$ value in Stata at 0.1 increments from 0.0 to 0.9. The difference in mean effect size between the RCTs and SCRDs may be due to methodological differences between group and SCRD studies. Thus, the effect sizes are not directly comparable between the RCTs and the SCRD studies. Relatively large effect sizes are easier to detect through visual analysis and may explain the publication bias toward studies with larger effects for SCRD studies (Shadish et al., 2015, 2016). As described in the Moderator Analyses section, we did identify evidence of publication bias. Other meta-analyses that combine group and SCRD studies have also reported relatively larger mean effect sizes for SCRD studies (Barton et al., 2017). Based on visual analysis of the SCRD studies, 41 graphs (45\%) showed strong evidence, two (2\%) showed moderate evidence, and 48 (53\%) showed no evidence of a functional relation between the intervention with responsivity strategies and child prelinguistic and/or language skills. Opportunities to show a functional relation that showed strong evidence had a mean BC-SMD of $2.34(S D=2.18$, range: $0.56-5.36$ ). Those that showed no evidence had a mean BC-SMD of 0.67 ( $S D=0.49$, range: $-0.20-2.69$ ).

\section{Moderator Analyses}

The moderator analyses address our second research question about whether particular study features account for the observed heterogeneity. RCTs and SCRD studies were analyzed separately.

The Galbraith plots (Figs. 2 and 3 ) and $\tau^{2}$ values (0.19 and 0.67 for RCTs and SRCD designs, respectively) all provide evidence of substantial heterogeneity. We define heterogeneity as variation in estimated 'true effects' (Borenstein et al., 2009). This variation is differentiated from that due to spurious error in the computation of $\tau^{2}$ by considering the ratio of observed to expected variation across studies. The results show that there is notable dispersion of the effect sizes that is assumed to be real rather than spurious error. The larger $\tau^{2}$ value for SRCD studies than RCTs indicates greater dispersion in true effects for the SRCD studies than the RCTs. The Galbraith plot, which is an alternative to the forest plot for meta-analyses with a large number of effect sizes, displays more precise estimates further from the origin. The large number of effect sizes outside of the two parallel outer lines that represent that $95 \%$ confidence interval indicates substantial heterogeneity (Anzures-Cabrera \& Higgins, 2010).

\section{RCTs}

For the RCTs, six moderator analyses were planned (i.e., interventionist, time in intervention, proximity, boundedness, risk for CME, and publication status). Context-bound outcomes exhibited a larger mean effect size $(p<0.05$; $g=0.47$ ) than generalized or potentially context-bound outcomes combined $(g=0.24)$. These results indicate the participants exhibited larger changes in behaviors that are measured in situations very similar to the treatment sessions (i.e., context-bound) than those measured in situations that vary from the treatment context in setting, materials, and/or communication partner. No other moderator analyses yielded significant results. Due to missing details in the included reports, time in intervention could only be extracted for 18 of the 33 RCTs. As a result, the degrees of freedom were too low to complete the analysis for time in intervention. Only a few studies that included caregivers as the interventionists reported the time caregivers spent conducting the intervention (Clionsky, 2012; Dawson et al., 2010; Green et al., 2010). As an alternative intensity variable, we tested time in intervention in weeks. However, even with more studies providing such information, the degrees of freedom were still too low (i.e., $<4$ ) for a trustworthy result. Similarly, due to studies rarely being unpublished (i.e., four effect sizes from two studies), the degrees of freedom for this analysis were too low to interpret. 
Table 5 Participant characteristics for included single case research design studies

\begin{tabular}{|c|c|c|c|c|c|c|}
\hline Reference & Pub & Loc & $n$ & $M$ age (mths) & $\begin{array}{l}\text { T1 Developmental Level } M \\
\text { (range) }\end{array}$ & ASD Severity $M$ (range) \\
\hline Becker, (2015) & No & USA* & 4 & 41 & $\begin{array}{l}\text { MSEL Composite SS: } 60 \\
(49-80)\end{array}$ & ADOS-2 severity: $8(6-10)$ \\
\hline Biller, (2018) & No & USA & 4 & 51 & MSEL VR AE: 25.5 (24-27) & NR \\
\hline Calise et al., (2009) & Yes & USA* & 1 & 150 & NR & NR \\
\hline Carpenter, (2003) & No & USA* & 3 & 69 & $\begin{array}{l}\text { VABS Daily Living AE: } 19 \\
(n=1)\end{array}$ & NR \\
\hline $\begin{array}{l}\text { Christensen-Sandfort \& Whin- } \\
\text { nery, (2013) }\end{array}$ & Yes & USA* & 3 & 63 & NR & CARS: 38.67 (32-45.5) \\
\hline $\begin{array}{l}\text { Coolican, (2010) \& Coolican } \\
\text { et al., (2010) }\end{array}$ & Mixed & Canada & 3 & 52 & $\begin{array}{l}\text { IQ percentile (varied tests): } 6 \\
(<1-16)\end{array}$ & NR \\
\hline Douglas et al., (2018) & Yes & USA & 3 & 52 & NR & NR \\
\hline Dykstra et al., (2012) & Yes & USA & 3 & 50 & $\begin{array}{l}\text { Leiter-R IQ: } 71(n=1) \text {; MSEL } \\
\text { AE: } 43 \& 46\end{array}$ & $\begin{array}{l}\text { ADOS Social Affect: } 13.67 \\
(12-17)\end{array}$ \\
\hline Gouvousis, (2012) & No & USA & 3 & 49 & NR & $\begin{array}{l}\text { CARS-2: "mildly-moderately" to } \\
\text { "severely" }\end{array}$ \\
\hline $\begin{array}{l}\text { Harjusola-Webb \& Robbins, } \\
\text { (2012) }\end{array}$ & Yes & USA & 3 & 36 & $\begin{array}{l}\text { VABS-II Expressive AE: } 11 \\
(8-16)\end{array}$ & CARS: 43 (40-47.5) \\
\hline Higgins, (1999) & No & USA & 3 & 46 & $\begin{array}{l}\text { VABS Cognitive AE: } 11.67 \\
(8-21)\end{array}$ & NR \\
\hline Hu et al., (2018) & Yes & China & 3 & 64 & $\begin{array}{l}\text { Chinese WPPSI IQ: } 107.67 \\
(104-112)\end{array}$ & Chinese CARS-2: 30.67 (30-32) \\
\hline Huskens et al., (2012) & Yes & USA* & 5 & 134 & $\begin{array}{l}\text { WISC-III NL IQ: } 112.25 \\
(105-121)\end{array}$ & NR \\
\hline Hwang \& Hughes, (2000) & Yes & USA* & 3 & 37 & $\begin{array}{l}\text { Uzgiris-Hunt: } 8-12 \text { or } 12-18 \mathrm{~m} \\
\text { range }\end{array}$ & NR \\
\hline Ingersoll et al., (2005) & Yes & USA* & 3 & 36 & $\begin{array}{l}\text { Bayley or Brigance MA: } 22 \\
(19-25)\end{array}$ & NR \\
\hline Ingersoll et al., (2007) & Yes & $\mathrm{USA}^{*}$ & 5 & 41 & $\begin{array}{l}\text { Bayley or MSEL MA: } 24.4 \\
\quad(16-31)\end{array}$ & CARS: 37.9 (32-44.5) \\
\hline $\begin{array}{l}\text { Ingersoll, (2003) \& Ingersoll \& } \\
\text { Schreibman, (2006) }\end{array}$ & Mixed & $\mathrm{USA}^{*}$ & 5 & 37 & Bayley MA: 19.8 (15-29) & $\begin{array}{l}\text { CARS: } 35.4(31.5-42) \text {; ADOS: } \\
14.8(13-16)\end{array}$ \\
\hline Ingersoll \& Wainer, (2013) & Yes & USA* & 5 & 48 & Bayley NV MA: 29.2 (27-31) & NR \\
\hline Jobin, (2013) & No & USA $^{*}$ & 4 & 26 & $\begin{array}{l}\text { MSEL EL T-score: } 24.5 \\
(<20-30)\end{array}$ & NR \\
\hline Laski et al., (1988) & Yes & $\mathrm{USA}^{*}$ & 8 & 78 & MA: $3.56(1.7-6.6)$ & NR \\
\hline Law et al., (2018) & Yes & Singapore & 3 & 42 & VABS AB SS: 66.33 (63-70) & NR \\
\hline Ma, (2010) & No & USA & 3 & 49 & NR & NR \\
\hline $\begin{array}{l}\text { Mancil, (2008) \& Mancil et al., } \\
\text { (2009) }\end{array}$ & Mixed & USA* & 3 & 67 & MA: 36.67 (29-49) & $\begin{array}{l}\text { ADI reciprocal social interaction: } \\
26 \text { (26), communication: } 17.33 \\
\text { (14-22), repetitive behaviors: } \\
10(10)\end{array}$ \\
\hline McGee et al., (1985) & Yes & USA & 3 & 32 & VABS AE: $3.77(2.2-5.3)$ & NR \\
\hline McGee \& Daly, (2007) & Yes & USA * & 3 & 59 & $\begin{array}{l}\text { Receptive vocabulary AE: } 36 \\
\quad(30->48)\end{array}$ & NR \\
\hline Nichols, (2014) & No & USA* & 4 & 42 & NR & NR \\
\hline Ogletree et al., (2012) & Yes & USA & 1 & 84 & NR & NR \\
\hline Penney \& Schwartz, (2019) & Yes & USA* & 3 & 58 & PPVT SS: 69 (55-96) & NR \\
\hline $\begin{array}{l}\text { Pierce, (1996) \& Pierce \& } \\
\text { Schreibman, (1997) }\end{array}$ & Mixed & USA* & 2 & 90 & NV IQ: 63 (50-76) & NR \\
\hline Randolph et al., (2011) & Yes & USA & 3 & 60 & VABS AB SS: 63.33 (55-71) & NR \\
\hline Rocha et al., (2007) & Yes & USA & 3 & 32 & Bayley NV MA: 14.67 (12-18) & NR \\
\hline Rollins et al., (2016) & Yes & USA & 4 & 30 & VB-MAPP milestones: 12 (8-15) & $\begin{array}{l}\text { CARS: } 44.63(39.5-47) \text {; ADOS-2 } \\
\text { total score: } 22(20-25)\end{array}$ \\
\hline
\end{tabular}


Table 5 (continued)

\begin{tabular}{|c|c|c|c|c|c|c|}
\hline Reference & Pub & Loc & $n$ & $M$ age (mths) & $\begin{array}{l}\text { T1 Developmental Level } M \\
\text { (range) }\end{array}$ & ASD Severity $M$ (range) \\
\hline Russell, (2014) & No & USA & 3 & 57 & NR & NR \\
\hline Schertz \& Odom, (2007) & Yes & USA* & 2 & 24 & $\begin{array}{l}\text { HELP Cognitive AE: } 15.75 \\
\quad(15-16.5)\end{array}$ & CARS: 42.75 (40.5-45) \\
\hline Sze, (2007) & No & USA & 4 & 26 & $\begin{array}{l}\text { VABS Communication AE: } 11.5 \\
(9-14)\end{array}$ & NR \\
\hline Therrien \& Light, (2018) & Yes & USA & 3 & 52 & PPVT SS: 60.67 (51-69) & CARS: 34.17 (30.5-36.5) \\
\hline Thiemann \& Goldstein, (2004) & Yes & USA* & 5 & 91 & Full scale IQ: 85.33 (47-117) & CARS: 33.7 (30-45.5) \\
\hline Thiemann-Bourque et al., (2017) & Yes & USA* & 3 & 54 & PLS-4 Total SS: 50 (50) & "Severe" \\
\hline Vernon et al., (2012) & Yes & USA* & 3 & 38 & $\begin{array}{l}\text { VABS Communication AE: } \\
18.33(15-24)\end{array}$ & NR \\
\hline Vogler-Elias, (2009) & No & USA & 3 & 54 & P-TONI SS: 113 (106-120) & CARS: 36.33 (30-47.5) \\
\hline $\begin{array}{l}\text { Whalen, (2001) \& Whalen \& } \\
\text { Schreibman, (2003) }\end{array}$ & Mixed & USA & 4 & 50 & Bayley MA: 18 (16-21) & $\begin{array}{l}\text { CARS: } 31.25 \text { (30-32.5); GARS: } \\
93.75 \text { (90-105) }\end{array}$ \\
\hline Zimmer, (2015) & No & USA & 4 & 33 & NR & NR \\
\hline
\end{tabular}

$A B$ adaptive behavior, ADI Autism Diagnostic Interview (Lord et al., 1994), ADOS Autism Diagnostic Observation Schedule (Lord et al., 1999), $A E$ age equivalent, $A S D$ autism spectrum disorder, Bayley Bayley Scales of Infant \& Toddler Development (Bayley, 1993), CARS Childhood Autism Rating Scale (Schopler et al., 1993); Brigance=Brigance Inventory of Early Development-Revised (Brigance, 1991), CARS-2 Childhood Autism Rating Scale (Second Edition; Lu et al., 2004; Schopler et al., 2010), EL expressive language, GARS Gilliam Autism Rating Scale (Gilliam, 1995), HELP Hawaii Early Learning Profile (Parks, 1992), IQ intelligence quotient, Leiter-R Leiter International Performance Scale-Revised (Roid \& Miller, 1997), Loc. location, $M$ mean, MA mental age, MSEL Mullen Scales of Early Learning (Mullen, 1995), mths months, $N R$ not reported, $N V$ nonverbal, PLS-4 Preschool Language Scale - Fourth Edition (Zimmerman et al., 2002), PPVT Peabody Picture Vocabulary Test (Dunn \& Dunn, 1997), P-TONI Primary Test of Nonverbal Intelligence (Ehrier \& McGhee, 2008), Pub. published, SS standard score, $T 1$ Time 1 / prior to intervention, USA United States of America, Uzgiris-Hunt Uzgiris-Hunt Ordinal Scales of Intellectual Development (Uzgiris-Hunt, 1975), VABS Vineland Adaptive Behavior Scales (Sparrow et al., 1984), VB-MAPP Verbal Behavior Milestones Assessment and Placement Program (Sundberg, 2008), VR Visual Reception, WISC-III NL Wechsler Intelligence Scale for Children - Netherlands (Kort et al., 2005), WPPSI Wechsler Preschool \& Primary Scale of Intelligence - Fourth Edition (Li et al., 2011; Wechsler, 2012)

Table 11 displays results by subgroups to inform decisions regarding which moderators may warrant additional investigation. Of note, the mean effect size was greater than zero for effect sizes at risk for CME $(g=0.39)$, but not for those free from CME risk $(g=0.12)$. Except for the caregiver only subgroup, the relatively low number of studies in the interventionist subgroups resulted in low degrees of freedom and should be interpreted with caution.

We calculated the correlations between each of the tested moderators to evaluate how distinct each moderator is from the others. Of all the pairs, only three exceeded $r=0.30$ : proximity of the outcome measure and time in intervention in weeks $(r=0.34)$, risk for CME and boundedness $(r=0.68)$, and time in intervention in weeks and time in intervention in hours $(r=0.75)$. Distal outcome measures were more likely to be used for studies of relatively longer duration. Studies not at risk for CME were more likely to use generalized outcome measures. The relatively high correlation between the time in intervention in weeks and time in intervention in hours is expected; time in intervention in weeks was derived as an alternative to time in intervention in hours to address missing data in the included reports.

A publication bias was not detected via the moderator analysis. However, the Egger's test suggests publication bias against small studies with negative results (Fig. $4 ; p<0.01$ ). The moderator analysis for publication bias was likely limited by the relatively low number of effect sizes (i.e., four) reported from unpublished reports (Fig. 5).

\section{SCRD Studies}

For the SCRD studies, three moderator analyses (i.e., interventionist, time in intervention, and publication bias) were completed. The other moderators tested for the RCTs did not have enough variation across the SCRD studies. All of the effect sizes were at risk for CME and used context-bound outcome measures. Only 7 effect sizes included distal outcome measures. For time in intervention, only 13 studies reported the necessary details. None of the moderator effects were significant. See Table 12 for moderator analyses by subgroup. No correlations between moderators exceeded $r=0.4$. We completed a follow-up analysis comparing only studies implemented by a caregiver alone or a clinician alone, which were the two types of interventionists with sufficient degrees of freedom for reliable results. Effect sizes for interventions implemented by caregivers only had a mean effect size of 0.81 versus 1.90 for those implemented 
Table 6 Intervention features of included single case research design studies

\begin{tabular}{|c|c|c|c|c|c|}
\hline Study & Intervention & Ind. or Group & Amount of intervention & Duration & Interventionist \\
\hline Becker, (2015) & $\begin{array}{l}\text { CATE for Joint Attention } \\
\text { Intervention }\end{array}$ & Ind & 4 30-min sessions/wk & $\sim 30$ sessions & Clinician \\
\hline Biller, (2018) & NTS and SPS & Ind & 2-3 30-min sessions/wk & $6-7$ mths & Clinician \\
\hline Calise et al., (2009) & Contingent imitation & Ind & 2 h/weekday & 12 sessions & Clinician \\
\hline Carpenter, (2003) & $\begin{array}{l}\text { Naturalistic teaching } \\
\text { strategies }\end{array}$ & Ind & $\begin{array}{l}\text { 10-min sessions (fre- } \\
\text { quency NR) }\end{array}$ & 18.7 sessions (mean) & Clinician \\
\hline $\begin{array}{l}\text { Christensen-Sandfort \& } \\
\text { Whinnery, (2013) }\end{array}$ & $\begin{array}{l}\text { Milieu teaching strate- } \\
\text { gies }\end{array}$ & Both & 2 20-min sessions/wk & 15-27 sessions & Educator \\
\hline $\begin{array}{l}\text { Coolican, (2010) \& } \\
\text { Coolican et al., (2010) }\end{array}$ & PRT & Ind & Varied (4-10 h/wk) & 2 mths & Caregiver \\
\hline Douglas et al., (2018) & $\begin{array}{l}\text { Online communication } \\
\text { partner training }\end{array}$ & Ind & Unable to determine & $2-3 \mathrm{wks}$ & Caregiver \\
\hline Dykstra et al., (2012) & ASAP & Ind & $\begin{array}{l}40+\min 1: 1 \& \\
10-15 \text { min group/wk }\end{array}$ & 7.5-14 wks & Educator \\
\hline Gouvousis, (2012) & PRT & Ind & Unable to determine & $6-11$ sessions & Educator \\
\hline $\begin{array}{l}\text { Harjusola-Webb \& Rob- } \\
\text { bins, (2012) }\end{array}$ & $\begin{array}{l}\text { Naturalistic commu- } \\
\text { nication- promoting } \\
\text { strategies }\end{array}$ & NR & $20-40 \mathrm{~min}$ & 6 mths & Educator \\
\hline Higgins, (1999) & $\begin{array}{l}\text { Semantic Pragmatic- } \\
\text { Developmental inter- } \\
\text { vention format }\end{array}$ & NR & 1-3 30-min sessions/wk & 10 sessions & Clinician \\
\hline Hu et al., (2018) & $\begin{array}{l}\text { Peer-Mediated LEGO® } \\
\text { Play }\end{array}$ & Group & 2 40-min sessions/wk & 14-21 sessions & Peer \\
\hline Huskens et al., (2012) & PRT & Ind & 1-2 20-min sessions/wk & $3-4 \mathrm{wks}$ & Day treatment staff \\
\hline $\begin{array}{l}\text { Hwang \& Hughes, } \\
\text { (2000) }\end{array}$ & $\begin{array}{l}\text { Social interactive train- } \\
\text { ing }\end{array}$ & Ind & 210 -min observations & 30 wks & Clinician \\
\hline Ingersoll et al., (2005) & DSP intervention & Ind & 2 50-min sessions/wk & $10 \mathrm{wks}$ & Clinician \\
\hline Ingersoll et al., (2007) & RIT & Ind & $\begin{array}{l}6 \text { 20-min sessions/wk (3 } \\
\text { sessions/day) }\end{array}$ & 10 wks & Clinician \\
\hline $\begin{array}{l}\text { Ingersoll, (2003) \& } \\
\text { Ingersoll \& Schreib- } \\
\text { man, (2006) }\end{array}$ & RIT & Ind & 820 -min sessions/wk & $10 \mathrm{wks}$ & Clinician \\
\hline $\begin{array}{l}\text { Ingersoll \& Wainer, } \\
\text { (2013) }\end{array}$ & Project ImPACT & Ind & $1-2$ 60-min sessions/wk & 12 wks & Caregiver \\
\hline Jobin, (2013) & PRT & Ind & 3 45-min sessions/wk & 12 wks & Clinician \\
\hline Laski et al., (1988) & $\begin{array}{l}\text { Natural Language } \\
\text { Paradigm }\end{array}$ & Ind & $\begin{array}{l}60 \mathrm{~min} / \mathrm{wk} \text { w/caregiver } \\
\& \text { clinic visits }\end{array}$ & 12 wks & Caregiver \\
\hline Law et al., (2018) & $\begin{array}{l}\text { Map4speech with natural } \\
\text { language intervention }\end{array}$ & Ind & $15 \mathrm{~min} /$ day 5 days/wk & Varied $($ mean $=6.7 \mathrm{wks})$ & Caregiver \\
\hline Мa, (2010) & $\begin{array}{l}\text { Naturalistic joint atten- } \\
\text { tion intervention }\end{array}$ & Ind & $40 \mathrm{~min} /$ day & $3-4$ wks & Caregiver \\
\hline $\begin{array}{l}\text { Mancil, (2008) \& Mancil } \\
\text { et al., (2009) }\end{array}$ & $\begin{array}{l}\text { Modified milieu therapy } \\
\text { intervention }\end{array}$ & Ind & 2-3 5-min sessions/wk & 24-33 sessions & Caregiver \\
\hline McGee et al., (1985) & Incidental teaching & Ind & 45 min/weekday & NR & Educator \\
\hline McGee \& Daly, (2007) & Incidental teaching & Group & $5 \mathrm{~min} /$ weekday & 17-43 sessions & Clinician or educator \\
\hline Nichols, (2014) & $\begin{array}{l}\text { Naturalistic Behavior } \\
\text { Strategies }\end{array}$ & Ind & $40-60 \mathrm{~min}$ & 13-21 sessions & Clinician \\
\hline Ogletree et al., (2012) & Milieu teaching sequence & Ind & $\begin{array}{l}210-\text { min sessions } 2-3 \\
\text { times/wk }\end{array}$ & 15 sessions over 7 wks & Clinician \\
\hline $\begin{array}{l}\text { Penney \& Schwartz, } \\
\text { (2019) }\end{array}$ & RIT & Ind & $\begin{array}{l}100 \text { min with caregiver; } \\
30-40 \text { min coaching } \\
\text { (child present) }\end{array}$ & $6-7 \mathrm{wks}$ & Caregiver \\
\hline $\begin{array}{l}\text { Pierce, (1996) \& Pierce } \\
\text { \& Schreibman, (1997) }\end{array}$ & PRT (peer-implemented) & Ind & 1-2 10-min sessions/day & 4-7 sessions & Peer \\
\hline Randolph et al., (2011) & PRT & Ind & Unable to determine & $5 \mathrm{wks}$ & Caregiver \& clinician \\
\hline
\end{tabular}


Table 6 (continued)

\begin{tabular}{|c|c|c|c|c|c|}
\hline Study & Intervention & Ind. or Group & Amount of intervention & Duration & Interventionist \\
\hline Rocha et al., (2007) & $\begin{array}{l}\text { Joint attention parent } \\
\text { training (DTT and PRT } \\
\text { components) }\end{array}$ & Ind & $\begin{array}{l}320 \text {-min sessions/day } 3 \\
\text { times/wk }\end{array}$ & 6 wks & Caregiver \& clinician \\
\hline Rollins et al., (2016) & $\begin{array}{l}\text { Pathways Early Autism } \\
\text { Intervention }\end{array}$ & Ind & 90-min session/wk & $8-13$ wks & Caregiver \\
\hline Russell, (2014) & PRT & Ind & Unable to determine & $1 \mathrm{wk}$ & Caregiver \\
\hline Schertz \& Odom, (2007) & JAML & Ind & $1 \mathrm{~h}$ per day & $9-26$ wks & Caregiver \\
\hline Sze, (2007) & $\begin{array}{l}\text { High-probability } \\
\text { Behavioral Momentum } \\
\text { Sequence }\end{array}$ & Ind & $15-30 \mathrm{~h}$ & $1-2$ wks & Clinician \\
\hline Therrien \& Light, (2018) & $\begin{array}{l}\text { Multicomponent inter- } \\
\text { vention with } \\
\text { AAC and turn-taking } \\
\text { training }\end{array}$ & Dyad & $\begin{array}{l}\text { 1-3 5-20 min sessions/ } \\
\text { wk }\end{array}$ & 5-9 sessions & Clinician \\
\hline $\begin{array}{l}\text { Thiemann \& Goldstein, } \\
\text { (2004) }\end{array}$ & Peer training and WTT & Ind & $\begin{array}{l}\text { WTT 75-100 min; } \\
\text { 10-min peer sessions } \\
\text { (frequency NR) }\end{array}$ & 21-37 sessions & Peer \& clinician \\
\hline $\begin{array}{l}\text { Thiemann-Bourque } \\
\text { et al., (2017) }\end{array}$ & Stay, Play, Talk & Dyad & $\begin{array}{l}2 \text { sessions/wk (unknown } \\
\text { length) }\end{array}$ & 15-18 sessions & Peer \\
\hline Vernon et al., (2012) & $\begin{array}{l}\text { PRT plus embedded } \\
\text { social interaction }\end{array}$ & Ind & 3-5 1-h sessions/wk & 16 sessions & Caregiver \\
\hline Vogler-Elias, (2009) & $\begin{array}{l}\text { Shared storybook read- } \\
\text { ing instruction }\end{array}$ & Ind & $\begin{array}{l}5 \text { min w/caregiver daily; } \\
3 \text { sessions w/caregiver } \\
\& \text { researcher/wk }\end{array}$ & 12 sessions & Caregiver \\
\hline $\begin{array}{l}\text { Whalen, (2001) \& } \\
\text { Whalen \& Schreibman, } \\
\text { (2003) }\end{array}$ & Joint attention training & Ind & $\begin{array}{l}325 \text {-min sessions/day } \\
3 \text { days/wk }\end{array}$ & $\sim 10 \mathrm{wks}$ & Clinician \\
\hline Zimmer, (2015) & MITS & Ind & $\begin{array}{l}\text { 30-min sessions (fre- } \\
\text { quency NR) }\end{array}$ & 4 sessions & Caregiver \\
\hline
\end{tabular}

$A A C$ augmentative and alternative communication, ASAP Advancing social-communication and play, CATE Complexity Account of Treatment Efficacy, DSP Developmental, Social-Pragmatic, DTT discrete trial training, $h r$ hour, Ind.Individual, ImPACT IMproving Parents As Communication Teachers, JAML Joint Attention Mediated Learning, min minute, MITS Meaningful Interactions Through Storybooks, $m t h$ month, NR not reported, NTS natural teaching strategies, PRT Pivotal Response Training/Treatment, RIT Reciprocal Imitation Training, SPS speech production strategies, $w k$ week, WTT written text treatment

by clinicians only. Results approached, but did not reach, statistical significance $(p=0.06)$. Given the magnitude of difference in mean effect sizes and identified differences in prior meta-analyses, the role of interventionists warrants continued evaluation in the future, especially as the number of relevant primary studies increases. A publication bias was not detected via the moderator analysis. However, like the RCT analysis, the Egger's test suggests publication bias against small studies with negative results $(p<0.001)$.

\section{Discussion}

\section{Summary of Evidence}

Based on 294 effect sizes from 33 RCTs and 69 effect sizes from 34 SCRD studies that included a total of 1040 participants, the weighted mean effect size of the effect of interventions using responsivity intervention strategies on child prelinguistic and language outcomes is moderate to large. The identified mean effect size $(g=0.36)$ is somewhat larger than that identified by Hampton and Kaiser (2016; $g=0.26$ ) and Sandbank et al., (2020b; $g=0.13$ for receptive language; $g=0.18$ for expressive language;), which evaluated a wider variety of interventions on language outcomes. Visual analysis of 91 opportunities to demonstrate a functional relation from 37 SCRD studies provided somewhat weaker support, characterized by $45 \%$ of opportunities showing strong support, $2 \%$ showing moderate support, and $53 \%$ showing no support for the interventions improving child prelinguistic and/or language outcomes. Thus, heterogeneity in results is apparent through the effect sizes and visual analysis. Although the mean effect size for the SCRD studies was large, a nearly even split between "strong" and 
Table 7 Visual analysis and effect size results for included single case research design studies

\begin{tabular}{|c|c|c|c|c|c|c|c|c|}
\hline & Design & Quality & Outcome measure(s) & Demos. of FR & FR Opps & Strength of evidence & $\#$ of $E S \mathrm{~s}$ & Mean $E S$ \\
\hline Becker, (2015) & MB-P & w/o res & $\begin{array}{l}\text { Initiating \& respond- } \\
\text { ing to points, gives, } \\
\& \text { gaze shifts }\end{array}$ & 0 & 7 & No & 7 & 0.31 \\
\hline Biller, (2018) & MP-P & w/res & Production score & 1 & 1 & Strong & 1 & 2.44 \\
\hline Calise et al., (2009) & ABABAB & w/res & $\begin{array}{l}\text { Vocalizations per } \\
\text { minute }\end{array}$ & 1 & 1 & Strong & $\mathrm{CNC}$ & $\mathrm{CNC}$ \\
\hline Carpenter, (2003) & MB-P & w/o res & $\begin{array}{l}\text { Coordinated JA; } \\
\text { spontaneous speech } \\
\text { \& verbalizations }\end{array}$ & CNA & CNA & N/A & 4 & 0.88 \\
\hline $\begin{array}{l}\text { Christensen-Sandfort } \\
\text { \& Whinnery, (2013) }\end{array}$ & MB-P & w/res & $\begin{array}{l}\text { Spontaneous } \\
\text { responses }\end{array}$ & 1 & 2 & Strong: 1 ; No: 1 & 2 & 1.16 \\
\hline $\begin{array}{l}\text { Coolican, (2010) } \\
\text { \& Coolican et al., } \\
(2010)\end{array}$ & MB-P & w/res & $\begin{array}{l}\text { Functional verbal } \\
\text { utterances }\end{array}$ & CNA & CNA & N/A & 1 & 0.85 \\
\hline Douglas et al., (2018) & MP-P & w/res & $\begin{array}{l}\text { Child communication } \\
\text { turns }\end{array}$ & 0 & 1 & No & 1 & 0.28 \\
\hline Dykstra et al., (2012) & MB-P & w/o res & Social communication & 0 & 2 & No & 2 & 0.70 \\
\hline Gouvousis, (2012) & MB-P & w/o res & $\begin{array}{l}\text { Spontaneous, } \\
\text { prompted, \& echoic } \\
\text { words \& phrases }\end{array}$ & 2 & 6 & Strong: 2 ; No: 4 & 6 & 1.09 \\
\hline $\begin{array}{l}\text { Harjusola-Webb \& } \\
\text { Robbins, (2012) }\end{array}$ & MB-P & w/o res & $\begin{array}{l}\text { Expressive communi- } \\
\text { cation }\end{array}$ & 1 & 1 & Strong & 1 & 2.20 \\
\hline Higgins, (1999) & AATD & w/o res & $\begin{array}{l}\text { Verbal \& nonverbal } \\
\quad \text { (semiotic) behaviors }\end{array}$ & 2 & 6 & Strong: 2; No: 4 & $\mathrm{CNC}$ & $\mathrm{CNC}$ \\
\hline Hu et al., (2018) & $\mathrm{ABAB}$ & w/o res & $\begin{array}{l}\text { Social initiations \& } \\
\text { responses }\end{array}$ & 2 & 2 & Strong & $\mathrm{CNC}$ & $\mathrm{CNC}$ \\
\hline Huskens et al., (2012) & MB-P & w/res & $\begin{array}{l}\text { Initiatives; spontane- } \\
\text { ous initiatives }\end{array}$ & 1 & 2 & Moderate: 1 ; No: 1 & 2 & 0.50 \\
\hline $\begin{array}{l}\text { Hwang \& Hughes, } \\
\text { (2000) }\end{array}$ & MB-P & w/res & JA & 1 & 1 & Strong & 1 & 2.61 \\
\hline Ingersoll et al., (2005) & MB-P & w/res & $\begin{array}{l}\text { Spontaneous expres- } \\
\text { sive language }\end{array}$ & CNA & CNA & N/A & 1 & 1.17 \\
\hline Ingersoll et al., (2007) & MB-P & w/o res & $\begin{array}{l}\text { Imitation \& spontane- } \\
\text { ous use of gestures }\end{array}$ & 2 & 4 & Strong: 2 ; No: 2 & 4 & 1.36 \\
\hline $\begin{array}{l}\text { Ingersoll, (2003) \& } \\
\text { Ingersoll \& Schreib- } \\
\text { man, (2006) }\end{array}$ & MB-P & w/o res & $\begin{array}{l}\text { Imitated \& sponta- } \\
\text { neous language; } \\
\text { coordinated JA; } \\
\text { coordinated JA w/ } \\
\text { PA }\end{array}$ & CNA & $\mathrm{CNA}$ & N/A & 5 & 0.88 \\
\hline $\begin{array}{l}\text { Ingersoll \& Wainer, } \\
\text { (2013) }\end{array}$ & MB-P & w/o res & Spontaneous language & 0 & 1 & No & 1 & 0.39 \\
\hline Jobin, (2013) & AATD & w/o res & $\begin{array}{l}\text { Acquired \& general- } \\
\text { ized receptive \& } \\
\text { expressive language }\end{array}$ & 6 & 16 & Strong: 6; No: 10 & $\mathrm{CNC}$ & $\mathrm{CNC}$ \\
\hline Laski et al., (1988) & MB-P & $\mathrm{w} / \mathrm{res}$ & Child vocalizations & 1 & 3 & Strong: 1; No: 2 & 3 & 1.47 \\
\hline Law et al., (2018) & MB-P & w/o res & $\begin{array}{l}\text { Prompted utterances } \\
\text { \& points }\end{array}$ & 0 & 1 & No & 1 & 0.25 \\
\hline Ma, (2010) & MB-P & w/res & $\begin{array}{l}\text { Independent initiating } \\
\text { JA }\end{array}$ & 1 & 1 & Strong & 1 & 1.33 \\
\hline $\begin{array}{l}\text { Mancil, (2008) \& } \\
\text { Mancil et al., (2009) }\end{array}$ & MB-P & w/o res & $\begin{array}{l}\text { Communication } \\
\text { responses }\end{array}$ & 1 & 1 & Strong & 1 & 2.21 \\
\hline McGee et al., (1985) & MB-P & w/o res & $\begin{array}{l}\% \text { correct on acquisi- } \\
\text { tion probe }\end{array}$ & 1 & 1 & Strong & $\mathrm{CNC}$ & $\mathrm{CNC}$ \\
\hline McGee \& Daly, (2007) & MB-P & w/o res & $\begin{array}{l}\text { Conversational } \\
\text { phrases per min }\end{array}$ & 1 & 1 & Strong & 1 & 0.70 \\
\hline
\end{tabular}


Table 7 (continued)

\begin{tabular}{|c|c|c|c|c|c|c|c|c|}
\hline & Design & Quality & Outcome measure(s) & Demos. of FR & FR Opps & Strength of evidence & \# of ESs & Mean $E S$ \\
\hline Nichols, (2014) & MB-P & w/o res & $\begin{array}{l}\text { Mands (total, } \\
\text { unprompted, with } \\
\text { social engagement) }\end{array}$ & 3 & 3 & Strong & 3 & 3.05 \\
\hline Ogletree et al., (2012) & MB-B & w/res & Trained exchanges & 0 & 1 & No & $\mathrm{CNC}$ & $\mathrm{CNC}$ \\
\hline $\begin{array}{l}\text { Penney \& Schwartz, } \\
\text { (2019) }\end{array}$ & MB-P & w/res & Spontaneous imitation & 0 & 1 & No & 1 & 0.44 \\
\hline $\begin{array}{l}\text { Pierce, (1996) \& } \\
\text { Pierce \& Schreib- } \\
\text { man, (1997) }\end{array}$ & MB-Peer & w/res & Initiations & 0 & 2 & No & $\mathrm{CNC}$ & $\mathrm{CNC}$ \\
\hline Randolph et al., (2011) & MB-P & w/res & $\begin{array}{l}\text { Verbal responses; } \\
\text { child initiations }\end{array}$ & 0 & 2 & No & 2 & 0.26 \\
\hline Rocha et al., (2007) & MB-P & w/res & $\begin{array}{l}\text { Responding to JA bids } \\
\text { (in sessions \& gen- } \\
\text { eralization probe) }\end{array}$ & 1 & 2 & Strong: 1 ; No: 1 & 2 & 1.74 \\
\hline Rollins et al., (2016) & MB-P & w/o res & Verbal reciprocity & $1^{*}$ & 1 & Moderate & 1 & 1.95 \\
\hline Russell, (2014) & MB-P & w/o res & $\begin{array}{l}\text { Functional verbal } \\
\text { utterances }\end{array}$ & 0 & 1 & No & 1 & 0.07 \\
\hline $\begin{array}{l}\text { Schertz \& Odom, } \\
\text { (2007) }\end{array}$ & MB-P & w/o res & $\begin{array}{l}\text { Turn-taking; initiating } \\
\text { \& responding to JA }\end{array}$ & 1 & 2 & Strong: 1 ; No: 1 & $\mathrm{CNC}$ & $\mathrm{CNC}$ \\
\hline Sze, (2007) & MB-P & w/o res & $\begin{array}{l}\text { Functional respond- } \\
\text { ing to target word } \\
\text { stimuli; number of } \\
\text { words; vocabulary } \\
\text { diversity }\end{array}$ & 3 & 3 & Strong & 3 & 3.85 \\
\hline $\begin{array}{l}\text { Therrien \& Light, } \\
\text { (2018) }\end{array}$ & MB-P & w/o res & Symbolic turns & 1 & 1 & Strong & 1 & 2.56 \\
\hline $\begin{array}{l}\text { Thiemann \& Gold- } \\
\text { stein, (2004) }\end{array}$ & MB-P \& MB-B & w/o res & $\begin{array}{l}\text { Social communication } \\
\text { skills }\end{array}$ & 5 & 7 & Strong: 5; No: 2 & 2 & 1.22 \\
\hline $\begin{array}{l}\text { Thiemann-Bourque } \\
\text { et al., (2017) }\end{array}$ & MP-P & w/o res & $\begin{array}{l}\text { Spontaneous com- } \\
\text { munication acts } \\
\text { directed to peers }\end{array}$ & 1 & 1 & Strong & 1 & 1.05 \\
\hline Vernon et al., (2012) & MB-P & w/o res & Verbal initiations & 1 & 1 & Strong & 1 & 1.23 \\
\hline Vogler-Elias, (2009) & MB-P & w/o res & $\begin{array}{l}\text { Number of different } \\
\text { words }\end{array}$ & 0 & 2 & No & 1 & 0.11 \\
\hline $\begin{array}{l}\text { Whalen, (2001) \& } \\
\text { Whalen \& Schreib- } \\
\text { man, (2003) }\end{array}$ & MB-P & w/res & $\begin{array}{l}\text { Following \& using } \\
\text { gaze shift \& point- } \\
\text { ing }\end{array}$ & CNA & CNA & N/A & 3 & 6.63 \\
\hline Zimmer, (2015) & MP-P & w/res & $\begin{array}{l}\text { JA behaviors per } \\
\text { minute }\end{array}$ & 1 & 1 & Strong & 1 & 4.59 \\
\hline
\end{tabular}

*Three demonstrations of an effect with one demonstration of a non-effect, but one participant who showed an effect began intervention at the same time as the participant who showed a non-effect; $A A T D$ adapted alternating treatments design, $C N A$ could not analyze, $C N C$ could not calculate, ES effect size, Demos. of FR number of demonstrations of a functional relation, FR Opps. opportunities to show a functional relation, $J A$ joint attention, $M B-B$ multiple baseline across behaviors, $M B-P$ multiple baseline across participants, $N / A$ not applicable, $P A$ positive affect, w/o res without reservations based on What Works Clearinghouse standards (What Works Clearinghouse, 2016), w/res with reservations based on What Works Clearinghouse standards (What Works Clearinghouse, 2016)

"no" evidence offers reason for caution in interpreting the results. Because many of the studies used a multiple baseline across participants design with three participants, the presence or absence of an effect for each participant could have a large impact on the overall judgment of a functional relation. In addition, the magnitude of effect sizes cannot be compared directly between the RCTs and SCRD studies due to methodological differences in study types.
Moderator analyses revealed that effect sizes using context-bound outcome measures had a larger mean effect size than those with potentially context-bound or generalized outcome measures for the RCTs. This finding is consistent with those reported by Yoder et al. (2013) and Fuller and Kaiser (2020) for social communication outcomes in children with ASD. In addition, RCTs at risk for CME exhibited a significant, positive effect size, but those free from CME risk did not. These results for the role of boundness and CME risk 
Table 8 Risk of bias for included randomized controlled trials

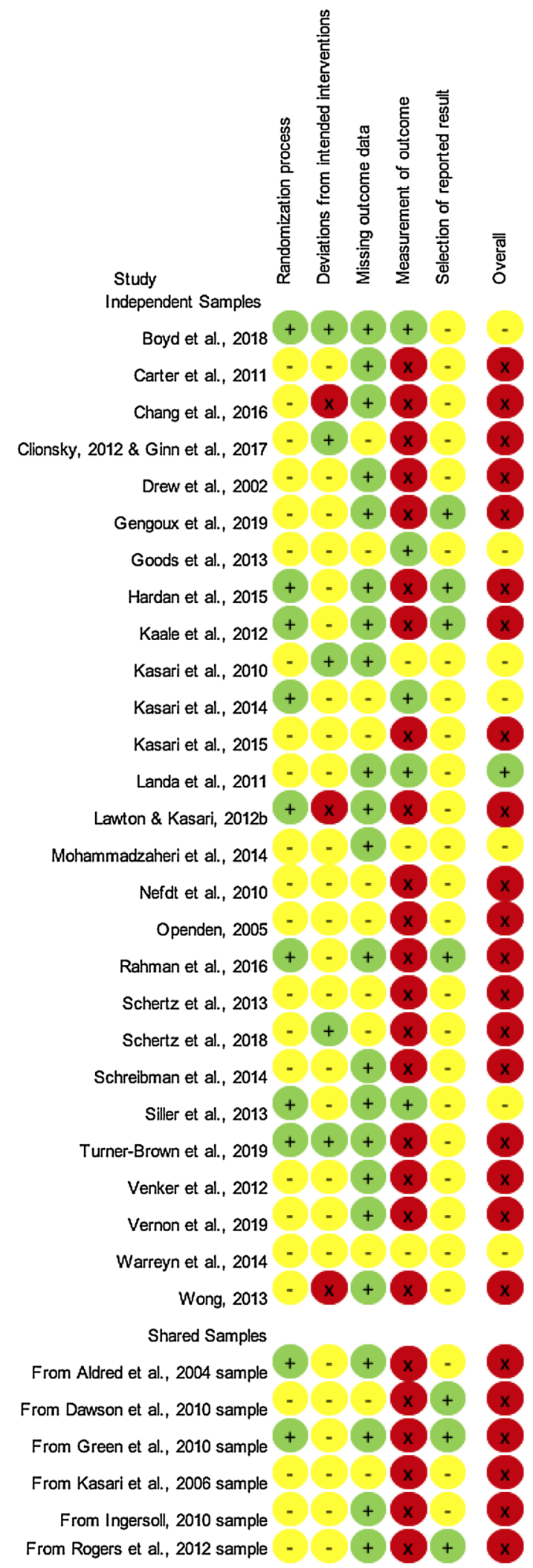

Note. Green circles indicate low risk of bias. Yellow circles indicate moderate risk of bias. Red circles indicate high risk of bias. 
Table 9 Procedural fidelity bias rating and outcome measure reliability for included randomized controlled trials

\begin{tabular}{|c|c|c|c|c|}
\hline & \multirow[t]{2}{*}{ PF Bias Rating } & \multicolumn{3}{|l|}{ Outcome Measure Reliability } \\
\hline & & Type & Value & $\%$ of sessions \\
\hline \multicolumn{5}{|l|}{ Independent samples } \\
\hline Boyd et al., (2018) & NI & ICC & $\begin{array}{l}.93 \text { (across all included OMs } \\
\text { from ADOS) }\end{array}$ & $20 \%$ \\
\hline Carter et al., (2011) & NI & ICC & $\begin{array}{l}\text { ESCS: .96; PCFP: .98; other } \\
\text { OMs: NR }\end{array}$ & Approximately $20 \%$ \\
\hline Chang et al., (2016) & PY & ICC & $\begin{array}{l}.92 \text { (across all included play } \\
\text { session OMs) }\end{array}$ & NR \\
\hline $\begin{array}{l}\text { Clionsky, (2012) \& Ginn } \\
\text { et al., (2017) }\end{array}$ & $\mathrm{PN}$ & Kappa & $\begin{array}{l}\text { Total child verbalizations: } \\
.66 \text {; word count: .13; other } \\
\text { OMs: NR }\end{array}$ & $27 \%$ \\
\hline Drew et al., (2002) & NI & NR & NR & NR \\
\hline Gengoux et al., (2019) & NI & $\mathrm{ICC}$ & $\begin{array}{l}\text { SLO: .94; BOSCC: .86; other } \\
\text { OMs: NR }\end{array}$ & $30 \%$ \\
\hline Goods et al., (2013) & NI & ICC & ESCS: .85; other OMs: NR & NR \\
\hline Hardan et al., (2015) & NI & ICC & SLO: .96; other OMs: NR & $>33 \%$ \\
\hline Kaale et al., (2012) & NI & ICC & $\begin{array}{l}\text { ESCS: .68; teacher-child } \\
\text { play: .62; mother-child } \\
\text { play: } .79\end{array}$ & $16-22 \%$ depending on $\mathrm{OM}$ \\
\hline Kasari et al., (2010) & $\mathrm{PN}$ & ICC & .78 & $20 \%$ \\
\hline Kasari et al., (2014) & NI & ICC & .80 & NR \\
\hline Kasari et al., (2015) & NI & ICC & IJA: .97; RDLS: NR & NR \\
\hline Landa et al., (2011) & NI & ICC & IJA: .95; MSEL: NR & $20 \%$ \\
\hline Lawton \& Kasari, (2012b) & PY & ICC & $\begin{array}{l}\text { Classroom observation: .77; } \\
\text { ESCS: .89; play observa- } \\
\text { tion: } .85\end{array}$ & $20 \%$ \\
\hline $\begin{array}{l}\text { Mohammadzaheri et al., } \\
\text { (2014) }\end{array}$ & NI & Percent agreement & CCC: .99; MLU: NR & $40 \%$ \\
\hline Nefdt et al., (2010) & NI & Point-by-point agreement & $93 \%$ & $35 \%$ \\
\hline Openden, (2005) & NI & Point-by-point agreement & $\begin{array}{l}\text { Functional verbal utterances: } \\
\text { 91\%; responsivity to oppor- } \\
\text { tunities: } 93 \%\end{array}$ & $\geq 33 \%$ \\
\hline Rahman et al., (2016) & NI & ICC & DCMA: 85; other OMs: NR & $20 \%$ \\
\hline Schertz et al., (2013) & NI & Kappa & PJAM: .80; other OMs: NR & $25 \%$ \\
\hline Schertz et al., (2018) & $\mathrm{PN}$ & NR & NR & NR \\
\hline $\begin{array}{l}\text { Schreibman \& Stahmer, } \\
\text { (2014) }\end{array}$ & NI & NR & NR & NR \\
\hline Siller et al., (2013) & NI & NR & NR & NR \\
\hline Turner-Brown et al., (2019) & PN & NR & NR & NR \\
\hline Venker et al., (2012) & NI & ICC & .96 across all OMs & $20 \%$ \\
\hline Vernon et al., (2019) & NI & NR & NR & NR \\
\hline Warreyn \& Roeyers, (2014) & NI & Kappa & $\begin{array}{l}\text { JA: .60-.93; imitation: } \\
\quad .72-.85\end{array}$ & $15 \%$ \\
\hline Wong, (2013) & PY & ICC & .86 & NR \\
\hline \multicolumn{5}{|l|}{ Shared samples } \\
\hline $\begin{array}{l}\text { From Aldred et al., (2004) } \\
\text { sample }\end{array}$ & $\mathrm{NI}$ & Percent agreement / kappa & $\begin{array}{l}\text { Parent-child interaction: } 90 \% \\
\text { /.89; other OMs: NR }\end{array}$ & $25 \%$ \\
\hline $\begin{array}{l}\text { From Dawson et al., (2010) } \\
\text { sample }\end{array}$ & NI & NR & NR & NR \\
\hline
\end{tabular}


Table 9 (continued)

PF Bias Rating Outcome Measure Reliability

\begin{tabular}{|c|c|c|c|c|}
\hline & & Type & Value & $\%$ of sessions \\
\hline $\begin{array}{l}\text { From Green et al., (2010) } \\
\text { sample }\end{array}$ & NI & ICC & $\begin{array}{l}\text { Parent-child interaction: .59; } \\
\text { ADOS standard scoring .79; } \\
\text { ADOS modified scoring: } \\
.83 \text {; child initiations: .8; } \\
\text { conversation turns: .9; other } \\
\text { OMs: NR }\end{array}$ & $\begin{array}{l}\text { Parent-child interaction: } 14 \% \text {; } \\
\text { ADOS: } 10 \% \text {; child initia- } \\
\text { tions \& conversational turns: } \\
22 \text { ratings }\end{array}$ \\
\hline $\begin{array}{l}\text { From Kasari et al., (2006) } \\
\text { sample }\end{array}$ & NI & $\begin{array}{l}\text { ESCS: Kappa / ICC; mother- } \\
\text { child interaction: ICC; JA } \\
\text { probe: Kappa }\end{array}$ & $\begin{array}{l}\text { ESCS: .79/.81; mother-child } \\
\text { interaction: .85; JA probe } \\
\text { (Gulsrud et al., 2007): .88; } \\
\text { RDLS \& EVT: NR }\end{array}$ & $\begin{array}{l}\text { ESCS: } 20 \% \text {; mother-child } \\
\text { interaction: NR; JA probe: } \\
25 \%\end{array}$ \\
\hline $\begin{array}{l}\text { From Ingersoll, (2010) } \\
\text { sample }\end{array}$ & NI & $\begin{array}{l}\text { MIS and UIA: Kappa; ESCS: } \\
\text { small/large }\end{array}$ & $\begin{array}{l}\text { MIS: .93; UIA: .84; ESCS: } \\
\quad 80 \%\end{array}$ & $25 \%$ \\
\hline $\begin{array}{l}\text { From Rogers et al., (2012) } \\
\text { sample }\end{array}$ & NI & NR & NR & NR \\
\hline
\end{tabular}

The PF Bias Rating is based on the Revised Cochrane risk-of-bias tool for randomized trials (Higgins et al., 2019). Point-by-point agreement is the number of agreements divided by the total number of agreements and disagreements multiplied by 100. ADOS Autism Diagnostic Observation Schedule (Lord et al., 1999), BOSCC Brief Observation of Social Communication Change (Grzadzinski et al., 2016), CCC Children's Communication Checklist (Bishop, 2006), DCMA Dyadic Communication Measure for Autism, ESCS Early Social Communication Scales (Mundy et al., 2003), EVT Expressive Vocabulary Test (Williams, 1997), ICC intraclass correlation coefficient, IJA initiating joint attention, $J A$ joint attention, MIS Motor Imitation Scale (Stone et al., 1997), MLU mean length of utterance, MSEL Mullen Scales of Early Learning (Mullen, 1995), NI No information or insufficient information, NR not reported, OMs outcome measures, $P C F P$ parent-child free play, $P F$ procedural fidelity, PJAM Precursors of Joint Attention Measure (Schertz, 2005), $P N$ probably no (not biased), $P Y$ probably yes (biased), RDLS Reynell Developmental Language Scales (Reynell \& Curwen, 1997), SLO structured laboratory observation, UIA Unstructured Imitation Assessment

could not be replicated for the SCRD studies because all of the SCRD study effect sizes were context-bound and at risk for CME. Although some of the SCRD studies did include generalization probes (e.g., with a different communication partner or setting), in the vast majority of cases probes were not frequent enough to meet quality standards for inclusion. Similarly, very few effect sizes from the SCRD studies

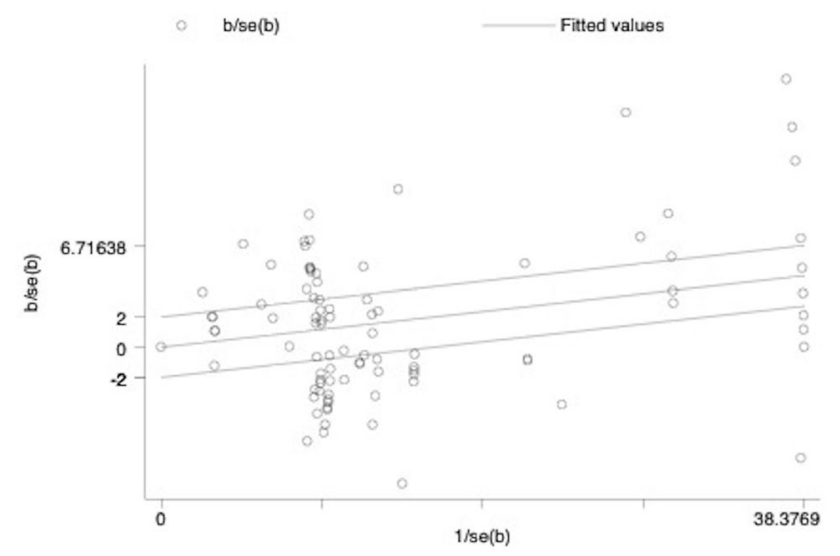

Fig. 2 Galbraith plot for included randomized controlled trials included distal outcome measures. Thus, proximity of the outcome measure could not be tested for the SCRD studies. Results for the RCTs and SCRD were consistent for publication bias being identified by the Egger's test but not the moderator analysis. The relatively small number of unpublished studies for both types of studies limited the moderator analysis. For both RCTs and SCRD studies, we were unable to test for a moderating effect of time in intervention, despite

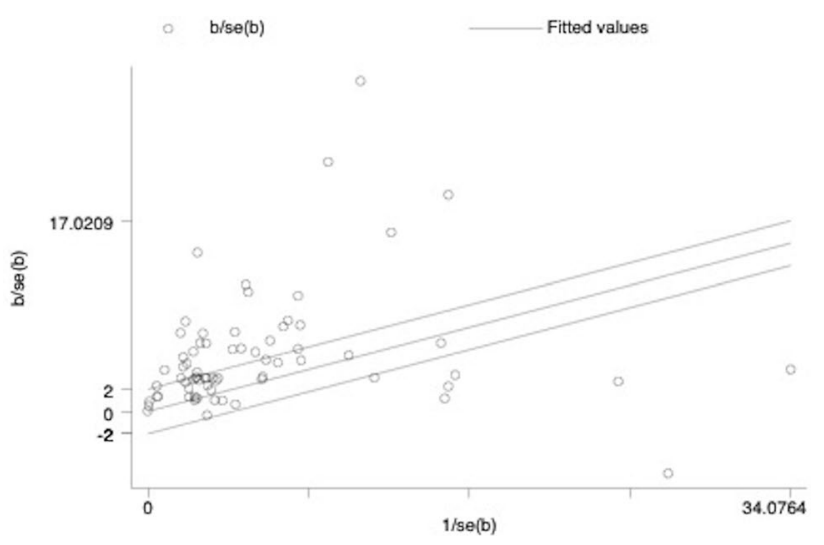

Fig. 3 Galbraith plot for included single case research design studies 
Table 10 Procedural fidelity for interventionist and interobserver agreement for included single case research design studies

\begin{tabular}{|c|c|c|c|c|c|}
\hline & \multicolumn{2}{|c|}{ Interventionist procedural fidelity } & \multicolumn{3}{|l|}{ Interobserver agreement } \\
\hline & Value & $\%$ of sessions & Type & Value & $\%$ of sessions \\
\hline Becker, (2015) & $\begin{array}{l}\text { No summary score; } \\
\text { describes selected inter- } \\
\text { vention steps }\end{array}$ & 26 & ICC & .99 & 24 \\
\hline Biller, (2018) & $\begin{array}{l}\text { "averaged at least } 90 \% \\
\text { across the six strategies" } \\
\text { (p. 52) }\end{array}$ & 25 & Point-by-point agreement & $90 \%$ & 25 \\
\hline Calise et al., (2009) & NR & NR & Frequency ratio & $95 \%$ & 33 (phases 5 \& 6) \\
\hline Carpenter, (2003) & NR & NR & Point-by-point agreement & $87 \%$ & $33-39$ \\
\hline $\begin{array}{l}\text { Christensen-Sandfort \& } \\
\text { Whinnery, (2013) }\end{array}$ & $100 \%$ & $7-13$ & Small/large & $94 \%$ & 28 \\
\hline $\begin{array}{l}\text { Coolican, (2010) \& Cooli- } \\
\text { can et al., (2010) }\end{array}$ & $\begin{array}{l}\text { No summary score; } 0,5, \\
\text { and } 4 \text { of } 8 \text { parents met } \\
75 \% \text { criteria at pre, post, } \\
\text { and follow-up phases }\end{array}$ & $>20$ & $\begin{array}{l}\text { Point-by-point agreement } \\
\text { / kappa }\end{array}$ & $86 \% / .85$ & 30 \\
\hline Douglas et al., (2018) & Not assessed & N/A & Point-by-point agreement & $97 \%$ & 21 \\
\hline Dykstra et al., (2012) & $91 \%$ & $15-20$ & Point-by-point agreement & $95-98 \%$ & $19-21$ \\
\hline Gouvousis, (2012) & $\begin{array}{l}\text { Teacher training phase: } \\
78 \% \text {; PRT treatment } \\
\text { phase: } 85 \%\end{array}$ & 100 & Point-by-point agreement & $93 \%$ & 40 \\
\hline $\begin{array}{l}\text { Harjusola-Webb \& Rob- } \\
\text { bins, (2012) }\end{array}$ & NR & NR & Point-by-point agreement & $89 \%$ & 20 \\
\hline Higgins, (1999) & NR & NR & Point-by-point agreement & $97 \%$ & Total of 122 -min segments \\
\hline Hu et al., (2018) & $100 \%$ & 36 & Point-by-point agreement & $88-91 \%$ & $33-40$ \\
\hline Huskens et al., (2012) & $97 \%$ & 33 & Point-by-point agreement & $88-98 \%$ & 33 \\
\hline Hwang \& Hughes, (2000) & $\begin{array}{l}\text { No summary value; } \\
\text { frequency of training } \\
\text { strategy use in Table } 5\end{array}$ & 100 & $\begin{array}{l}\text { Point-by-point agreement } \\
\text { / kappa }\end{array}$ & $86 \% / .79$ & 28 \\
\hline Ingersoll et al., (2005) & .90 & 10 & Kappa & .61 & 25 \\
\hline Ingersoll et al., (2007) & .96 & 10 & Kappa & $.66-.73$ & 25 \\
\hline $\begin{array}{l}\text { Ingersoll, (2003) \& } \\
\text { Ingersoll \& Schreibman, } \\
\text { (2006) }\end{array}$ & .96 & 10 & Kappa & $.73-.94$ & 33 \\
\hline Ingersoll \& Wainer, (2013) & $\begin{array}{l}\text { No summary value; } \\
\text { graphed }\end{array}$ & 100 & ICC & .93 & 25 \\
\hline Jobin, (2013) & .99 & 33 & Point-by-point agreement & $91 \%$ & 33 \\
\hline Laski et al., (1988) & NR & NR & Point-by-point agreement & $87-96 \%$ & 49 \\
\hline Law et al., (2018) & $\begin{array}{l}\text { 83-97\% depending on } \\
\text { phase }\end{array}$ & 100 & Percentage & $85-97 \%$ & 33 \\
\hline Мa, (2010) & $\begin{array}{l}98 \% \text { (averaged across all } \\
\text { phases) }\end{array}$ & $17-100$ & Point-by-point agreement & $92-100 \%$ & $17-100$ \\
\hline $\begin{array}{l}\text { Mancil, (2008) \& Mancil } \\
\text { et al., (2009) }\end{array}$ & $92 \%$ & 100 & $\begin{array}{l}\text { Point-by-point agreement } \\
\text { / kappa }\end{array}$ & $95 \% / .90$ & $50-100$ \\
\hline McGee et al., (1985) & NR & NR & Point-by-point agreement & $99 \%$ & 21 \\
\hline McGee \& Daly, (2007) & $\begin{array}{l}\text { No summary value pro- } \\
\text { vided }\end{array}$ & NR & Occurrence agreement & $90 \%$ & 25 \\
\hline Nichols, (2014) & $100 \%$ & 30 & Small/large & $95 \%$ & 25 \\
\hline Ogletree et al., (2012) & $100 \%$ & $<20$ & Point-by-point agreement & $83 \%$ & $30 \%$ of opportunities \\
\hline Penney \& Schwartz, (2019) & $87 \%$ & $\sim 20$ & Point-by-point agreement & $95 \%$ & 22 \\
\hline $\begin{array}{l}\text { Pierce, (1996) \& Pierce \& } \\
\text { Schreibman, (1997) }\end{array}$ & NR & NR & Point-by-point agreement & $92 \%$ & 33 \\
\hline Randolph et al., (2011) & $\begin{array}{l}2 \text { of } 3 \text { caregivers reached } \\
\text { the } 80 \% \text { criterion during } \\
\text { intervention }\end{array}$ & 100 & Point-by-point agreement & $94 \%$ & $27-50$ \\
\hline
\end{tabular}


Table 10 (continued)

\begin{tabular}{|c|c|c|c|c|c|}
\hline & \multicolumn{2}{|c|}{ Interventionist procedural fidelity } & \multicolumn{3}{|l|}{ Interobserver agreement } \\
\hline & Value & $\%$ of sessions & Type & Value & $\%$ of sessions \\
\hline Rocha et al., (2007) & $91 \%$ & $25->29$ & $\begin{array}{l}\text { Point-by-point agreement } \\
\text { / kappa }\end{array}$ & $84 \% / .94$ & $>33$ \\
\hline Rollins et al., (2016) & $85 \%$ & 100 & Kappa & $99 \%$ & 20 \\
\hline Russell, (2014) & $46 \%$ & NR & Pearson's correlation & .99 & 25 \\
\hline Schertz \& Odom, (2007) & $\begin{array}{l}\text { No summary value; see } \\
\text { Table } 2\end{array}$ & NR & Kappa & .83 & 25 \\
\hline Sze, (2007) & $100 \%$ & 33 & Point-by-point agreement & $95-98 \%$ & 33 \\
\hline Therrien \& Light, (2018) & $99 \%$ & 30 & Point-by-point agreement & $94 \%$ & 30 \\
\hline $\begin{array}{l}\text { Thiemann \& Goldstein, } \\
\text { (2004) }\end{array}$ & $>80 \%$ & 25 & Point-by-point agreement & $90 \%$ & 33 \\
\hline $\begin{array}{l}\text { Thiemann-Bourque et al., } \\
\text { (2017) }\end{array}$ & $92 \%$ & 41 & Point-by-point agreement & $92 \%$ & 30 \\
\hline Vernon et al., (2012) & $93 \%$ & 50 & $\begin{array}{l}\text { Point-by-point agreement } \\
\text { / kappa }\end{array}$ & $90 \% / .77$ & 33 \\
\hline Vogler-Elias, (2009) & NR & NR & NR & NR & NR \\
\hline $\begin{array}{l}\text { Whalen, (2001) \& Whalen } \\
\text { \& Schreibman, (2003) }\end{array}$ & $93-100 \%$ & 10 & $\begin{array}{l}\text { Point-by-point agreement } \\
\text { / kappa }\end{array}$ & $>80 \% / .87$ & 33 \\
\hline Zimmer, (2015) & NR & NR & Point-by-point agreement & $88 \%$ & 33 \\
\hline
\end{tabular}

Point-by-point agreement is the number of agreements divided by the total number of agreements and disagreements multiplied by 100 . NR not reported

attempts to use multiple intensity variables. Too few studies included key details about intensity in the included reports.

In sum, these findings provide support for the use of responsivity intervention strategies for children with ASD for improving prelinguistic and language skills. As expected, findings are more robust for context-bound outcome measures than other types of outcome measures (e.g., potentially context-bound and generalized characteristics).

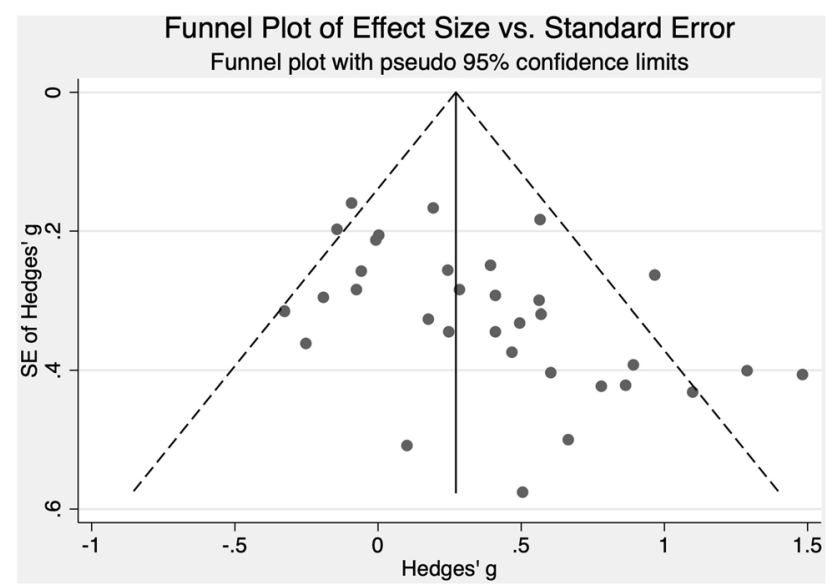

Fig. 4 Funnel plot of effect size (Hedges' g) versus standard error for included randomized controlled trials

\section{Limitations}

Limitations for meta-analyses are influenced by primary study level characteristics as well as meta-analytic level characteristics. For the current study, imprecise reporting at the primary study level, especially for the study's intensity, limited analyses. Despite calls for improved reporting of intervention details, only about half of the RCTs and SCRD studies provided sufficient information to determine the time in intervention, a less precise variable than the cumulative

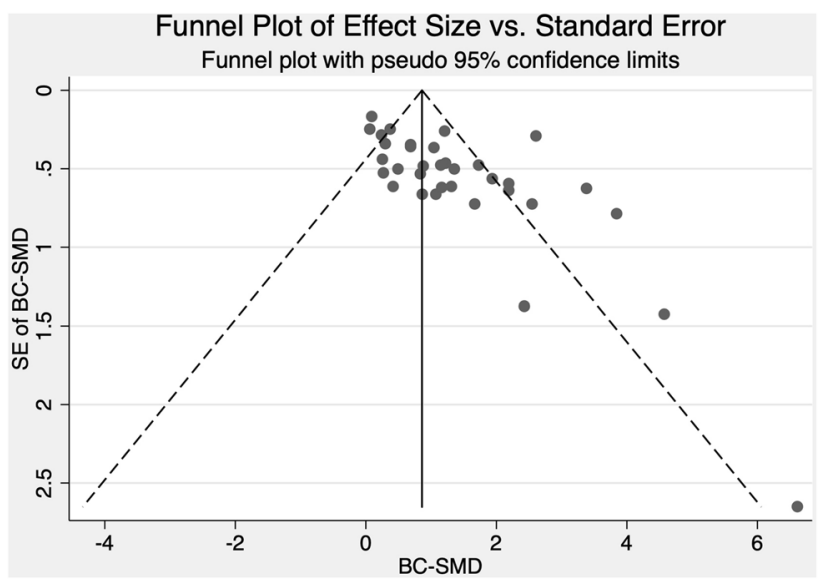

Fig. 5 Funnel plot of effect size (between-case standardized mean difference [BC-SMD]) versus standard error for included single case research design studies 
Table 11 Moderator analysis results by subgroup for included randomized controlled trials

\begin{tabular}{lllll}
\hline Subgroup & $n$ & $d f$ & $g$ & $95 \%$ CI \\
\hline Overall weighted mean effect size & 294 & 30.73 & 0.36 & {$[0.21,0.51]$} \\
Interventionist & & & & \\
$\quad$ Caregivers & 104 & 16.49 & 0.30 & {$[0.07,0.53]$} \\
Clinicians & 97 & 3.92 & - & - \\
$\quad$ Caregivers and clinicians & 55 & 4.83 & 0.31 & {$[-0.09,0.71]$} \\
$\quad$ Educators & 38 & 3.51 & - & - \\
Proximity of outcome measure & & & & \\
$\quad$ Proximal & 166 & 22.72 & 0.40 & {$[0.24,0.55]$} \\
$\quad$ Distal & 128 & 19.12 & 0.28 & {$[0.08,0.47]$} \\
Boundedness of outcome measure & & & & \\
Context-bound & 70 & 17.44 & 0.47 & {$[0.27,0.67]$} \\
Potentially context-bound & 57 & 13.67 & 0.21 & {$[0.03,0.39]$} \\
$\quad$ Generalized & 167 & 22.21 & 0.19 & {$[0.03,0.36]$} \\
Correlated measurement error & & & & \\
At risk & 145 & 25.29 & 0.39 & {$[0.22,0.56]$} \\
$\quad$ Not at risk & 149 & 18.77 & 0.12 & {$[-.03,0.27]$} \\
Published & 290 & 29.77 & 0.36 & {$[0.21,0.52]$} \\
$\quad$ Not published & 4 & 1.00 & - & - \\
\hline
\end{tabular}

When $d f$ is less than 4 , results are omitted because they should be interpreted with caution. $d f$ degrees of freedom, $n$ number of effect sizes, $g$ mean standardized group difference

Table 12 Moderator analysis results by subgroup for included single case research design studies

\begin{tabular}{llrll}
\hline Subgroup & $n$ & $d f$ & BC-SMD & $95 \%$ CI \\
\hline $\begin{array}{l}\text { Overall weighted mean effect } \\
\quad \text { size }\end{array}$ & 69 & 30.49 & 1.20 & {$[0.87,1.54]$} \\
$\quad$ Interventionist & & & & \\
$\quad$ Caregivers & 15 & 10.37 & 0.81 & {$[0.32,1.29]$} \\
$\quad$ Clinicians & 33 & 9.01 & 1.90 & {$[0.99,2.80]$} \\
$\quad$ Caregivers and clinicians & 4 & 1.00 & - & - \\
$\quad$ Educators & 12 & 3.54 & 1.06 & {$[0.32,1.79]$} \\
Published & 40 & 21.37 & 1.16 & {$[0.84,1.48]$} \\
Not published & 29 & 9.15 & 1.32 & {$[0.35,2.29]$} \\
\hline
\end{tabular}

When $d f$ is less than 4 , results are omitted because they should be interpreted with caution. $B C-S M D$ between-case standardized mean difference, $d f$ degrees of freedom, $n$ number of effect sizes

intervention intensity (Warren et al., 2007). Given the potential importance of treatment intensity for the effectiveness, cost (financial and time), and feasibility of services for children, reports of future studies would be strengthened by explicit descriptions of intensity variables. Concerns of study quality of the included studies also influenced the meta-analysis. Forty-four SCRD design studies that would have otherwise been included were excluded because they failed to meet What Works Clearinghouse standards. Risk for CME was very common across included studies and should be attended to in future studies to minimize risk for bias.

The use of meta-analytic analyses for SCRD studies is a relatively new and still developing area. As a result, only studies that used a multiple baseline across participants design were able to be included in the current quantitative meta-analysis. Future meta-analyses on responsivity intervention strategies should be considered as other analytic approaches develop. Other limitations at the meta-analytic level include the potential failure to include relevant effect sizes and only including studies written in English. The risk of missing relevant effect sizes was minimized through multiple supplementary searches and completion of reliability checks at all screening levels. Lastly, robust variance estimation is most effective with at least 40 studies. Our analyses using robust variance estimation included 33 RCTs and 34 SCRD studies.

\section{Strengths}

Although our searches yielded effect sizes from fewer than 40 RCTs or SCRD studies, the use of robust variance estimation remains a strength of this meta-analysis. Robust variance estimation permits the inclusion of multiple effect sizes per study, which eliminates the loss of potentially important effect sizes. Second, we include both RCTs and SCRD studies, which is currently rare for systematic reviews and meta-analyses. This approach provides a more comprehensive review of the current literature base and opportunities for replication across the two study types. Third, we enhanced the quality of this meta-analysis by conducting interrater reliability for all screening levels and having two independent coders extract data (including risk of bias) for all included reports. Fourth, we considered the quality of the included studies through multiple avenues. We not only required studies to meet certain characteristics to be included, but also coded for study quality features including risk for bias and CME.

\section{Clinical Implications}

This systematic review and meta-analysis provides empirical support for the use of responsivity intervention strategies to improve prelinguistic and language skills of children with ASD. Because the data are more robust for contextbound outcome measures (e.g., behaviors that occur during the intervention or a very similar setting) than generalized characteristics (e.g., use of targeted skills in a novel setting with someone other than the interventionist), gains in generalized characteristics should be monitored closely during clinical practice. The observed benefits of responsivity intervention strategies were observed for a wide variety of outcome measures (e.g., joint attention, use of gestures, 
verbal utterances, and vocalizations), which suggests that these strategies have broad application including both prelinguistic and early language skills.

\section{Research Implications}

Additional, high-quality intervention studies regarding the observed benefits of responsivity intervention strategies are needed to further delineate the specific impact of these strategies and how features of such interventions can be adjusted to maximize gains. At the primary study level, future studies would be enhanced by continued improvement of study quality, especially minimizing risk for bias and CME, and more explicit reporting of putative moderators of treatment effects.

The need to report intensity data was especially apparent. Not only is such data needed to determine whether more intensive intervention is likely to have positive or negative effects on child outcomes, but also to control for intensity when investigating the role of other putative moderators, such as interventionist. Explicit reporting will improve the effectiveness of future meta-analytic moderator analyses. Primary studies that directly address the effect of intensity on intervention are also needed.

Continued inclusion of distal outcome measures in coordination with proximal measures is also warranted. Explicitly identifying outcomes as proximal versus distal will allow readers to accurately weigh the results. Because distal measures are expected to yield smaller effect sizes than proximal measures, achieving a relatively large effect size for a distal measure should be noted. SCRD studies can be used within a programmatic line of research to guide selection of outcome measures in RCTs. For example, an SCRD may include some generalization and maintenance data with sufficient data points to determine whether those dependent variables may be suitable distal and/or generalized characteristic outcome measures for a subsequent RCT. The evidence base would also benefit from the inclusion of studies that provide specific responsivity intervention strategies outside of large treatment packages as well as explicit descriptions of strategies implemented. Such evidence would facilitate ongoing efforts to identify active ingredients of interventions and inform modifications aimed at increasing effectiveness.

\section{Conclusions}

This meta-analysis provides support for the use of responsivity intervention strategies with young children with ASD to support growth in prelinguistic and language skills. Positive results were observed for both RCTs and SCRD studies. Moderator analysis indicated the need to attend to the potential roles of CME and boundedness of outcome measures. Concerns of study quality, risk for bias, and omission of key intervention details were also observed. These findings can be applied to future studies to enhance the quality of the literature base and the confidence of clinical recommendations for intervention practices.

Supplementary Information The online version contains supplementary material available at https://doi.org/10.1007/s10803-021-05331-y.

Acknowledgements The authors thank Lily Black, Madeline Friedrichs, Mackenna Murphy, and Jordan Rangel for screening and coding records for this project.

Author Contributions JM conceived of and designed the study, drafted the coding manual, coded and interpreted the data, and drafted the manuscript; NCB and SFW helped design the study, participated in editing the coding manual and interpreting the data, and edited the manuscript. All authors read and approved the final manuscript.

Funding This research was supported by the National Institute of Child Health and Human Development (U54HD090216; Kansas Intellectual and Developmental Disabilities Research Center).

\section{Declarations}

Conflict of interest JM, NCB, and SFW declare that they have no conflict of interest.

Ethical Approval All authors read and approved the final manuscript. The authors thank Lily Black, Madeline Friedrichs, Mackenna Murphy, and Jordan Rangel for screening and coding records for this project.

Research involving Human Participants and/or Animals Not applicable.

Informed Consent Not applicable.

Open Access This article is licensed under a Creative Commons Attribution 4.0 International License, which permits use, sharing, adaptation, distribution and reproduction in any medium or format, as long as you give appropriate credit to the original author(s) and the source, provide a link to the Creative Commons licence, and indicate if changes were made. The images or other third party material in this article are included in the article's Creative Commons licence, unless indicated otherwise in a credit line to the material. If material is not included in the article's Creative Commons licence and your intended use is not permitted by statutory regulation or exceeds the permitted use, you will need to obtain permission directly from the copyright holder. To view a copy of this licence, visit http://creativecommons.org/licenses/by/4.0/.

\section{References}

\section{References marked with bullets indicate studies included in the meta-analysis}

- Aldred, C., Green, J., \& Adams, C. (2004). A new social communication intervention for children with autism: Pilot randomised 
controlled treatment study suggesting effectiveness. Journal of Child Psychology and Psychiatry, 45(8), 1420-1430. https://doi. org/10.1111/j.1469-7610.2004.00848.x

- Aldred, C., Green, J., Emsley, R., \& McConachie, H. (2012). Brief report: Mediation of treatment effect in a communication intervention for pre-school children with autism. Journal of Autism and Developmental Disorders, 42(3), 447-454. https://doi.org/ 10.1007/s10803-011-1248-3

Anderson, D. K., Lord, C., Risi, S., DiLavore, P. S., Shulman, C., Thurm, A., Welch, K., \& Pickles, A. (2007). Patterns of growth in verbal abilities among children with autism spectrum disorder. Journal of Consulting and Clinical Psychology, 75(4), 594-604. https://doi.org/10.1037/0022-006X.75.4.594

Anzures-Cabrera, J., \& Higgins, J. (2010). Graphical displays for metaanalysis: An overview with suggestions for practice. Research Synthesis Methods, 1(1), 66-80. https://doi.org/10.1002/jrsm.6

Baker, E. (2012). Optimal intervention intensity. International Journal of Speech-Language Pathology, 14(5), 401-409. https://doi.org/ 10.3109/17549507.2012.700323

Barton, E. E., Pustejovsky, J. E., Maggin, D. M., \& Reichow, B. (2017). Technology-aided instruction and intervention for students with ASD: A meta-analysis using novel methods of estimating effect sizes for single-case research. Remedial and Special Education, 38(6), 371-386. https://doi.org/10.1177/ 0741932517729508

Bayley, N. (1993). Bayley scales of infant development (2nd ed.). Harcourt Brace.

Bayley, N. (2005). Bayley scales of infant and toddler development (3rd ed.). Psychological Corporation.

- Becker, S. D. (2015). Evaluating the feasibility and effects of the Complexity Account of Treatment Efficacy (CATE) for joint attention intervention with children with ASD. (Publication No. AAI3646890). [Doctoral dissertation, University of Kansas]. ProQuest.

- Biller, M. F. (2018). A combined spoken communication intervention for children with autism spectrum disorder who are minimally verbal. (Publication No. AAI10831920) [Doctoral dissertation, University of Illinois at Urbana-Champaign]. Illinois Digital Environment for Access to Learning and Scholarship. http://hdl. handle.net/2142/97727.

Billstedt, E., Gillberg, C., \& Gillberg, C. (2005). Autism after adolescence: Population-based 13- to 22-year follow-up study of 120 individuals with autism diagnosed in childhood. Journal of Autism and Developmental Disorders, 35(3), 351-360. https:// doi.org/10.1007/s10803-005-3302-5

Bishop, D. V. M. (2006). Children's Communication Checklist (2nd ed., U.S. ed.). Psychological Corporation.

Borenstein, M., Hedges, L. V., Higgins, J. P. T., \& Rothstein, H. R. (2009). Introduction to meta-analysis. Wiley.

- Boyd, B. A., Watson, L. R., Reszka, S. S., Sideris, J., Alessandri, M., Baranek, G. T., Crais, E. R., Donaldson, A., Gutierrez, A., Johnson, L., \& Belardi, K. (2018). Efficacy of the ASAP intervention for preschoolers with ASD: A cluster randomized controlled trial. Journal of Autism and Developmental Disorders, 48(9), 3144-3162. https://doi.org/10.1007/s10803-018-3584-z

Brandel, J., \& Frome Loeb, D. (2011). Program intensity and service delivery models in the schools: SLP survey results. Language, Speech, and Hearing Services in Schools, 42(4), 461-490. https://doi.org/10.1044/0161-1461(2011/10-0019

Brigance, A. (1991). Brigance inventory of early development-Revised. Curriculum Associates.

- Calise, J., Cautilli, J., \& Galino, R. (2009). Can contingently imitating vocal response increase the frequency of vocal responses? The Journal of Speech and Language Pathology Applied Behavior Analysis, 3(2-3), 233-241.
Camarata, S., \& Yoder, P. (2002). Language transactions during development and intervention: Theoretical implications for developmental neuroscience. International Journal of Developmental Neuroscience, 20(3), 459-465. https://doi.org/10.1016/S07365748(02)00044-8

- Carpenter, H. M. (2003). Using naturalistic teaching strategies (NaTS) to promote coordinated joint attention and gestures in children with autism. (Publication No. AAI3079291). [Doctoral dissertation, Claremont Graduate University]. ProQuest.

- Carter, A. S., Messinger, D. S., Stone, W. L., Celimli, S., Nahmias, A. S., \& Yoder, P. (2011). A randomized controlled trial of Hanen's "More Than Words" in toddlers with early autism symptoms. Journal of Child Psychology and Psychiatry, 52(7), 741-752. https://doi.org/10.1111/j.1469-7610.2011.02395.x

- Chang, Y. C., Shire, S. Y., Shih, W., Gelfand, C., \& Kasari, C. (2016). Preschool deployment of evidence-based social communication intervention: JASPER in the classroom. Journal of Autism and Developmental Disorders, 46(6), 2211-2223. https://doi.org/10. 1007/s10803-016-2752-2

- Christensen-Sandfort, R. J., \& Whinnery, S. B. (2013). Impact of milieu teaching on communication skills of young children with autism spectrum disorder. Topics in Early Childhood Special Education, 32(4), 211-222. https://doi.org/10.1177/0271121411 404930

- Clionsky, L. N. (2012). Child directed interaction training for young children with autism spectrum disorders: The impact on child language, social skills, adaptive skills, and problematic behaviors. (Publication No. AAAI3647879). [Doctoral dissertation, University of Florida]. ProQuest Infomration \& Learning.

Cohen, I. L., Schmidt-Lackner, S., Romanczyk, R., \& Sudhalter, V. (2003). The PDD Behavior Inventory: A rating scale for assessing response to intervention in children with PDD. Journal of Autism and Developmental Disorders, 33(1), 31-45. https://doi. org/10.1023/A:1022226403878

Constantino, J. N., \& Gruber, C. P. (2005). The Social Responsiveness Scale Manual. Western Psychological Services.

Constantino, J. N. (2012). Social Responsiveness Scale. ( $2^{\text {nd }}$ ed.). Western Psychological Services.

- Coolican, J. (2010). Brief parent training in pivotal response treatment for preschoolers with autism. (Publication No. AAINR50055). [Doctoral dissertation, Dalhousie University]. ProQuest.

- Coolican, J., Smith, I. M., \& Bryson, S. E. (2010). Brief parent training in pivotal response treatment for preschoolers with autism. Journal of Child Psychology and Psychiatry, 51(12), 1321-1330. https://doi.org/10.1111/j.1469-7610.2010.02326.x

- Dawson, G., Jones, E. J. H., Merkle, K., Venema, K., Lowy, R., Faja, S., Kamara, D., Murias, M., Greenson, J., Winter, J., Smith, M., Rogers, S. J., \& Webb, S. J. (2012). Early behavioral intervention is associated with normalized brain activity in young children with autism. Journal of the American Academy of Child \& Adolescent Psychiatry, 51(11), 1150-1159. https://doi.org/10.1016/j. jaac.2012.08.018

- Dawson, G., Rogers, S., Munson, J., Smith, M., Winter, J., Greenson, J., Donaldson, A., \& Varley, J. (2010). Randomized, controlled trial of an intervention for toddlers with autism: The Early Start Denver Model. Pediatrics, 125(1), e17-e23. https://doi.org/10. 1542/peds.2009-0958

De Giacomo, A., \& Fombonne, E. (1998). Parental recognition of developmental abnormalities in autism. European Child \& Adolescent Psychiatry, 7(3), 131-136. https://doi.org/10.1007/s0078 70050058

- Douglas, S. N., Kammes, R., \& Nordquist, E. (2018). Online communication training for parents of children with autism spectrum disorder. Communication Disorders Quarterly, 39(3), 415-425. https://doi.org/10.1177/1525740117727491 
- Drew, A., Baird, G., Baron-Cohen, S., Cox, A., Slonims, V., Wheelwright, S., Swettenham, J., Berry, B., \& Charman, T. (2002). A pilot randomised control trial of a parent training intervention for pre-school children with autism. European Child \& Adolescent Psychiatry, 11(6), 266-272. https://doi.org/10.1007/ s00787-002-0299-6

Dunn, L. M., \& Dunn, L. M. (1997). Examiner's manual for the PPVTIII: Peabody Picture Vocabulary Test-Third Edition. American Guidance Service.

- Dykstra, J. R., Boyd, B. A., Watson, L. R., Crais, E. R., \& Baranek, G. T. (2012). The impact of the Advancing Social-communication and Play (ASAP) intervention on preschoolers with autism spectrum disorder. Autism, 16(1), 27-44. https://doi.org/10.1177/ 1362361311408933

Edmunds, S. R., Kover, S. T., \& Stone, W. L. (2019). The relation between parent verbal responsiveness and child communication in young children with or at risk for autism spectrum disorder: A systematic review and meta-analysis. Autism Research, 12(5), 715-731. https://doi.org/10.1002/aur.2100

Ehrier, D. J. \& McGhee, R. L. (2008). Primary Test of Nonverbal Intelligence (PTONI). Pro-Ed.

- Estes, A., Munson, J., Rogers, S. J., Greenson, J., Winter, J., \& Dawson, G. (2015). Long-term outcomes of early intervention in 6-year-old children with autism spectrum disorder. Journal of the American Academy of Child \& Adolescent Psychiatry, 54(7), 580-587. https://doi.org/10.1016/j.jaac.2015.04.005

Fenson, L., Dale, P. S., Reznick, J. S., Thal, D., Bates, E., Hartung, J. P., Pethick, S., \& Reilly, J. S. (1993). MacArthur Communicative Development Inventory: Users guide and technical manual. Norwich: Singular Publishing Company.

Fuller, E. A., \& Kaiser, A. P. (2020). The effects of early intervention on social communication outcomes for children with autism spectrum disorder: A meta-analysis. Journal of Autism and Developmental Disorders, 50(5), 1683-1700. https://doi.org/ 10.1007/s10803-019-03927-z

- Gengoux, G. W., Abrams, D. A., Schuck, R., Millan, M. E., Libove, R., Ardel, C. M., Phillips, J. M., Fox, M., Frazier, T. W., \& Hardan, A. Y. (2019). A pivotal response treatment package for children with autism spectrum disorder: An RCT. Pediatrics, 144(3), e20190178. https://doi.org/10.1542/peds.2019-0178

Gilliam, J. E. (1995). Gilliam autism rating scale. Pro-Ed.

- Ginn, N. C., Clinosky, L. N., Eyberg, S. M., Warner-Metzger, C., \& Abner, J.-P. (2017). Child-directed interaction training for young children with autism spectrum disorders: Parent and child outcomes. Journal of Clinical Child and Adolescent Psychology, 46(1), 101-109. https://doi.org/10.1080/15374416.2015.1015135

Goldstein, M. H., King, A. P., \& West, M. J. (2003). Social interaction shapes babbling: Testing parallels between birdsong and speech. Proceedings of the National Academy of Sciences, 100(13), 8030-8035. https://doi.org/10.1073/pnas.1332441100

Goldstein, M. H., \& Schwade, J. A. (2008). Social feedback to infants' babbling facilitates rapid phonological learning. Psychological Science, 19(5), 515-523. https://doi.org/10.1111/j.1467-9280. 2008.02117.x

- Goods, K. S., Ishijima, E., Chang, Y. C., \& Kasari, C. (2013). Preschool based JASPER intervention in minimally verbal children with autism: Pilot RCT. Journal of Autism and Developmental Disorders, 43(5), 1050-1056. https://doi.org/10.1007/ s10803-012-1644-3

- Gouvousis, A. (2012). Teacher implemented pivotal response training to improve communication in children with autism spectrum disorders. (Publication No. AAI3456462). [Doctoral dissertation, East Carolina University]. ProQuest.

- Green, J., Charman, T., McConachie, H., Aldred, C., Slonims, V., Howlin, P., Le Couteur, A., Leadbitter, K., Hudry, K., \& Byford, S. (2010). Parent-mediated communication-focused treatment in children with autism (PACT): A randomised controlled trial. The Lancet, 375(9732), 2152-2160. https://doi.org/10.1016/S01406736(10)60587-9

Griffiths, R. (1986). The abilities of babies. London: University of London Press.

Grzadzinski, R., Carr, T., Colombi, C., McGuire, K., Dufek, S., Pickles, A., \& Lord, C. (2016). Measuring changes in social communication behaviors: Preliminary development of the Brief Observation of Social Communication Change (BOSCC). Journal of Autism and Developmental Disorders, 46(7), 2464-2479. https:// doi.org/10.1007/s10803-016-2782-9

- Gulsrud, A. C., Kasari, C., Freeman, S., \& Paparella, T. (2007). Children with autism's response to novel stimuli while participating in interventions targeting joint attention or symbolic play skills. Autism, 11(6), 535-546. https://doi.org/10.1177/13623 61307083255

Guy, W. (1976). ECDEU assessment manual for psychopharmacology. US Department of Health, Education, and Welfare.

Hampton, L., \& Kaiser, A. (2016). Intervention effects on spokenlanguage outcomes for children with autism: A systematic review and meta-analysis. Journal of Intellectual Disability Research, 60(5), 444-463. https://doi.org/10.1111/jir.12283

- Hardan, A. Y., Gengoux, G. W., Berquist, K. L., Libove, R. A., Ardel, C. M., Phillips, J., Frazier, T. W., \& Minjarez, M. B. (2015). A randomized controlled trial of Pivotal Response Treatment Group for parents of children with autism. Journal of Child Psychology and Psychiatry, 56(8), 884-892. https:// doi.org/10.1111/jcpp.12354

- Harjusola-Webb, S. M., \& Robbins, S. H. (2012). The effects of teacher-implemented naturalistic intervention on the communication of preschoolers with autism. Topics in Early Childhood Special Education, 32(2), 99-110. https://doi.org/10.1177/ 0271121410397060

Hedges, L. V., Pustejovsky, J. E., \& Shadish, W. R. (2012). A standardized mean difference effect size for single case designs. Research Synthesis Methods, 3(3), 224-239. https://doi.org/ 10.1002/jrsm. 1052

Hedges, L. V., Pustejovsky, J. E., \& Shadish, W. R. (2013). A standardized mean difference effect size for multiple baseline designs across individuals. Research Synthesis Methods, 4(4), 324-341. https://doi.org/10.1002/jrsm.1086

Hedges, L. V., Tipton, E., \& Johnson, M. C. (2010). Robust variance estimation in meta-regression with dependent effect size estimates. Research Synthesis Methods, 1(1), 39-65. https:// doi.org/10.1002/jrsm.5

- Higgins, K. C. (1999). A comparative study of communication intervention for nonverbal children with autism. (Publication No. AAM9922084). [Doctoral dissertation, Louisiana State University and Agricultural and Mechanical College]. ProQuest.

Higgins, J. P., Savović, J., Page, M. J., Elbers, R. G., \& Sterne, J. A. (2019). Assessing risk of bias in a randomized trial. Cochrane Handbook for Systematic Reviews of Interventions. https://doi. org/10.1002/9781119536604

Howlin, P. (2000). Outcome in adult life for more able individuals with autism or Asperger syndrome. Autism, 4(1), 63-83. https://doi. org/10.1177/1362361300004001005

Howlin, P., \& Moore, A. (1997). Diagnosis in autism: A survey of over 1200 patients in the UK. Autism, 1(2), 135-162. https://doi.org/ $10.1177 / 1362361397012003$

- Hu, X., Zheng, Q., \& Lee, G. T. (2018). Using peer-mediated LEGO ${ }^{\circledR}$ play intervention to improve social interactions for Chinese children with autism in an inclusive setting. Journal of Autism and Developmental Disorders, 48(7), 2444-2457. https:// doi.org/10.1007/s10803-018-3502-4 
- Huskens, B., Reijers, H., \& Didden, R. (2012). Staff training effective in increasing learning opportunities for school-aged children with autism spectrum disorders. Developmental Neurorehabilitation, 15(6), 435-447. https://doi.org/10.3109/17518423.2012.705910

Huwaldt, J. A. (2010). PlotDigitizer. http://plotdigitizer.sourceforge. net/

- Hwang, B., \& Hughes, C. (2000). Increasing early social-communicative skills of preverbal preschool children with autism through social interactive training. Journal of the Association for Persons with Severe Handicaps, 25(1), 18-28. https://doi.org/10.2511/ rpsd.25.1.18

- Ingersoll, B. R. (2003). Teaching children with autism to imitate using a naturalistic treatment approach: Effects on imitation, language, play, and social behaviors. (Publication No. AAI3076342). [Doctoral dissertation, University of California, San Diego]. ProQuest.

- Ingersoll, B. (2010). Brief report: Pilot randomized controlled trial of reciprocal imitation training for teaching elicited and spontaneous imitation to children with autism. Journal of Autism and Developmental Disorders, 40(9), 1154-1160. https://doi.org/10. 1007/s10803-010-0966-2

- Ingersoll, B. (2012). Brief report: Effect of a focused imitation intervention on social functioning in children with autism. Journal of Autism and Developmental Disorders, 42(8), 1768-1773. https:// doi.org/10.1007/s10803-011-1423-6

- Ingersoll, B., Dvortcsak, A., Whalen, C., \& Sikora, D. (2005). The effects of a developmental, social-pragmatic language intervention on rate of expressive language production in young children with autistic spectrum disorders. Focus on Autism \& Other Developmental Disabilities, 20(4), 213-222. https://doi.org/10. 1177/10883576050200040301

- Ingersoll, B., Lewis, E., \& Kroman, E. (2007). Teaching the imitation and spontaneous use of descriptive gestures in young children with autism using a naturalistic behavioral intervention. Journal of Autism \& Developmental Disorders, 37(8), 1446-1456. https://doi.org/10.1007/s10803-006-0221-z

- Ingersoll, B., \& Schreibman, L. (2006). Teaching reciprocal imitation skills to young children with autism using a naturalistic behavioral approach: Effects on language, pretend play, and joint attention. Journal of Autism \& Developmental Disorders, 36(4), 487-505. https://doi.org/10.1007/s10803-006-0089-y

- Ingersoll, B., \& Wainer, A. (2013). Initial efficacy of project ImPACT: A parent-mediated social communication intervention for young children with ASD. Journal of Autism \& Developmental Disorders, 43(12), 2943-2952.

- Jobin, A. B. (2013). Integrating treatment strategies for children with autism. (Publication No. AAI3542620). [Doctoral dissertation, University of California, San Diego]. ProQuest.

- Kaale, A., Smith, L., \& Sponheim, E. (2012). A randomized controlled trial of preschool-based joint attention intervention for children with autism. Journal of Child Psychology and Psychiatry, 53(1), 97-105. https://doi.org/10.1111/j.1469-7610.2011. 02450.x

- Kasari, C., Freeman, S., \& Paparella, T. (2006). Joint attention and symbolic play in young children with autism: A randomized controlled intervention study. Journal of Child Psychology and Psychiatry, 47(6), 611-620. https://doi.org/10.1111/j.1469-7610. 2005.01567.x

- Kasari, C., Gulsrud, A., Paparella, T., Hellemann, G., \& Berry, K. (2015). Randomized comparative efficacy study of parent-mediated interventions for toddlers with autism. Journal of Consulting and Clinical Psychology, 83(3), 554-563. https://doi.org/10. 1037/a0039080

- Kasari, C., Gulsrud, A., Wong, C., Kwon, S., \& Locke, J. (2010). Randomized controlled caregiver mediated joint engagement intervention for toddlers with autism. Journal of Autism and
Developmental Disorders, 40(9), 1045-1056. https://doi.org/ 10.1007/s10803-010-0955-5

Kasari, C., Gulsrud, A., Freeman, S., Paparella, T., \& Hellemann, G. (2012). Longitudinal follow-up of children with autism receiving targeted interventions on joint attention and play. Journal of the American Academy of Child \& Adolescent Psychiatry, 51(5), 487-495. https://doi.org/10.1016/j.jaac.2012.02.019

- Kasari, C., Lawson, K., Shih, W., Barker, T. V., Landa, R., Lord, C., Orlich, F., King, B., Wetherby, A., \& Senturk, D. (2014). Caregiver-mediated intervention for low-resourced preschoolers with autism: An RCT. Pediatrics, 134(1), e72-79. https://doi.org/ 10.1542/peds.2013-3229

- Kasari, C., Paparella, T., Freeman, S., \& Jahromi, L. B. (2008). Language outcome in autism: Randomized comparison of joint attention and play interventions. Journal of Consulting and Clinical Psychology, 76(1), 125-137. https://doi.org/10.1037/0022-006x. 76.1.125

Kjelgaard, M. M., \& Tager-Flusberg, H. (2001). An investigation of language impairment in autism: Implications for genetic subgroups. Language and Cognitive Processes, 16(2-3), 287-308. https://doi.org/10.1080/01690960042000058

Kort, W., Schittekatte, M., Dekker, P. H., Verhaeghe, P., Compaan, E. L., Bosmans, M., \& Vermeir, G. (2005). WISC-III NL. Harcourt Test Publishers.

Kozlowski, A. M., Matson, J. L., Horovitz, M., Worley, J. A., \& Neal, D. (2011). Parents' first concerns of their child's development in toddlers with autism spectrum disorders. Developmental Neurorehabilitation, 14(2), 72-78. https://doi.org/10.3109/17518 423.2010.539193

Kratochwill, T., Hitchcock, J., Horner, R., Levin, J. R., Odom, S., Rindskopf, D., \& Shadish, W. (2010). Single-case designs technical documentation. What Works Clearinghouse.

- Landa, R. J., Holman, K. C., O'Neill, A. H., \& Stuart, E. A. (2011). Intervention targeting development of socially synchronous engagement in toddlers with autism spectrum disorder: A randomized controlled trial. Journal of Child Psychology and Psychiatry, 52(1), 13-21. https://doi.org/10.1111/j.1469-7610.2010. 02288.x

- Laski, K. E., Charlop, M. H., \& Schreibman, L. (1988). Training parents to use the natural language paradigm to increase their autistic children's speech. Journal of Applied Behavior Analysis, 21(4), 391-400. https://doi.org/10.1901/jaba.1988.21-391

- Law, G. C., Neihart, M., \& Dutt, A. (2018). The use of behavior modeling training in a mobile app parent training program to improve functional communication of young children with autism spectrum disorder. Autism, 22(4), 424-439. https://doi.org/10.1177/ 1362361316683887

- Lawton, K., \& Kasari, C. (2012a). Brief report: Longitudinal improvements in the quality of joint attention in preschool children with autism. Journal of Autism and Developmental Disorders, 42(2), 307-312. https://doi.org/10.1007/s10803-011-1231-z

- Lawton, K., \& Kasari, C. (2012b). Teacher-implemented joint attention intervention: Pilot randomized controlled study for preschoolers with autism. Journal of Consulting and Clinical Psychology, 80(4), 687-693. https://doi.org/10.1037/a0028506

Ledford, J., \& Gast, D. (Eds.). (2018). Single case research methodology: Applications in special education and behavioral sciences (3rd ed.). Oxfordshire: Routledge.

Li, Y. Q., Zhang, H. C., \& Zhu, J. J. (2011). Wei shi er tong zhi li liang biao di 4 ban (zhong wen ban) liu fen ce yan jian ban ji qi zai zhi li can ji ping ding zhong de zuo yong [Subtests Short Form of Wechsler Intelligence Scale for Children Fourth Edition-Chinese in Assessment of Intellectual Disabilities]. Zhongguo Kang Fu Li Lun Yushi Jian, 17(12), 1101-1104. 
Lord, C., Rutter, M., Dilavore, P., \& Risi, S. (1999). The autism diagnostic observation schedule (ADOS). Western Psychological Corporation.

Lord, C., Risi, S., \& Pickles, A. (2004). Trajectory of language development in autistic spectrum disorders. In Developmental language disorders (pp. 18-41). Psychology Press, England.

Lord, C., \& Paul, R. (1997). Language and communication in autism. In D. J. Cohen \& F. R. Volkmar (Eds.), Handbook of autism and pervasive development disorders (2nd ed., pp. 195-225). Wiley.

Lord, C., Rutter, M., \& Le Couteur, A. (1994). Autism Diagnostic Interview-Revised: A revised version of a diagnostic interview for caregivers of individuals with possible pervasive development disorders. Journal of Autism and Developmental Disorders, 24(5), 659-685. https://doi.org/10.1007/BF02172145

Lu, J. P., Yang, Z. W., Shu, M. Y., \& Su, L. Y. (2004). Er tong gu du zheng liang biao ping ding de xin du, xiao du fen xi [Reliability, validity analysis of the childhood autism rating scale]. Zhongguo Xian Dai Yi Xue Za Zhi, 13, 119-121.

- Ma, C. Q. (2010). Effects of a parent-implemented intervention on initiating joint attention in children with autism. (Publication No. AAI3367523). [Doctoral dissertation, University of South Carolina]. ProQuest.

- Mancil, G. R. (2008). Effects of a modified milieu therapy intervention on the social communicative behaviors of young children with autism spectrum disorders. (Publication No. AAI3281563). [Doctoral dissertation, University of Florida]. ProQuest.

- Mancil, G. R., Conroy, M. A., \& Haydon, T. F. (2009). Effects of a modified milieu therapy intervention on the social communicative behaviors of young children with autism spectrum disorders. Journal of Autism and Developmental Disorders, 39(1), 149-163. https://doi.org/10.1007/s10803-008-0613-3

McConachie, H., \& Diggle, T. (2007). Parent implemented early intervention for young children with autism spectrum disorder: A systematic review. Journal of Evaluation in Clinical Practice, 13(1), 120-129. https://doi.org/10.1111/j.1365-2753.2006.00674.x

McDuffie, A., \& Yoder, P. (2010). Types of parent verbal responsiveness that predict language in young children with autism spectrum disorder. Journal of Speech, Language, and Hearing Research, 53(4), 1026-1039. https://doi.org/10.1044/10924388(2009/09-0023)

- McGee, G. G., \& Daly, T. (2007). Incidental teaching of age-appropriate social phrases to children with autism. Research and Practice for Persons with Severe Disabilities, 32(2), 112-123. https:// doi.org/10.2511/rpsd.32.2.112

- McGee, G. G., Krantz, P. J., \& McClannahan, L. E. (1985). The facilitative effects of incidental teaching on preposition use by autistic children. Journal of Applied Behavior Analysis, 18(1), 17-31. https://doi.org/10.1901/jaba.1985.18-17

McLean, J., \& Snyder-McLean, L. (1978). A transactional approach to early language training. Merrill.

- Mohammadzaheri, F., Koegel, L. K., Rezaee, M., \& Rafiee, S. M. (2014). A randomized clinical trial comparison between pivotal response treatment (PRT) and structured applied behavior analysis (ABA) intervention for children with autism. Journal of Autism and Developmental Disorders, 44(11), 2769-2777. https://doi.org/10.1007/s10803-014-2137-3

Mullen, E. M. (1995). Mullen scales of early learning. American Guidance Service.

Mundy, P., Delgado, C., Block, J., Venezia, M., Hogan, A., \& Seibert, J. (2003). A manual for the abridged Early Social Communication Scales (ESCS). Miami: University of Miami.

Mundy, P., Sigman, M. D., Ungerer, J., \& Sherman, T. (1986). Defining the social deficits of autism: The contribution of non-verbal communication measures. Journal of Child Psychology and Psychiatry and Allied Disciplines, 27, 657-669. https://doi.org/10. 1111/j.1469-7610.1986.tb00190.x
- Nefdt, N., Koegel, R., Singer, G., \& Gerber, M. (2010). The use of a self-directed learning program to provide introductory training in pivotal response treatment to parents of children with autism. Journal of Positive Behavior Interventions, 12(1), 23-32. https:// doi.org/10.1177/1098300709334796

- Nichols, S. M. (2014). The effect of naturalistic behavior strategies on the quality of social interactions for children with autism. (Publication No. AAI3538123). [Doctoral dissertation, ProQuest]. ProQuest.

- Ogletree, B. T., Davis, P., Hambrecht, G., \& Wooten Phillips, E. (2012). Using milieu training to promote photograph exchange for a young child with autism. Focus on Autism \& Other Developmental Disabilities, 27(2), 93-101. https://doi.org/10.1177/ 1088357612441968

Oono, I. P., Honey, E. J., \& McConachie, H. (2013). Parent-mediated early intervention for young children with autism spectrum disorders (ASD). Cochrane Database of Systematic Reviews. https:// doi.org/10.1002/14651858.CD009774.pub2

- Openden, D. A. (2005). Pivotal response treatment for multiple families of children with autism: Probable efficacy and effectiveness of a group parent education workshop. (Publication No. 3174384). [Doctoral dissertation, University of California, Santa Barbara]. ProQuest.

Parks, S. (1992). HELP® Strands. VORT Corporation.

Patten, E., Belardi, K., Baranek, G. T., Watson, L. R., Labban, J. D., \& Oller, D. K. (2014). Vocal patterns in infants with autism spectrum disorder: Canonical babbling status and vocalization frequency. Journal of Autism and Developmental Disorders, 44(10), 2413-2428. https://doi.org/10.1007/s10803-014-2047-4

- Penney, A., \& Schwartz, I. (2019). Effects of coaching on the fidelity of parent implementation of reciprocal imitation training. Autism, 23(6), 1497-1507. https://doi.org/10.1177/1362361318816688

- Pickles, A., Le Couteur, A., Leadbitter, K., Salomone, E., ColeFletcher, R., Tobin, H., Gammer, I., Lowry, J., Vamvakas, G., Byford, S., Aldred, C., Slonims, V., McConachie, H., Howlin, P., Parr, J. R., Charman, T., \& Green, J. (2016). Parent-mediated social communication therapy for young children with autism (PACT): Long-term follow-up of a randomised controlled trial. Lancet, 388(10059), 2501-2509. https://doi.org/10.1016/s01406736(16)31229-6

- Pierce, K. L. (1996). The assessment and treatment of social behavior in autism: Towards a naturalistic approach. (Publication No. AAM9633344). [Doctoral dissertation, University of California, San Diego]. ProQuest.

- Pierce, K., \& Schreibman, L. (1997). Multiple peer use of pivotal response training to increase social behaviors of classmates with autism: Results from trained and untrained peers. Journal of Applied Behavior Analysis, 30(1), 157-160. https://doi.org/ 10.1901/jaba.1997.30-157

Pustejovsky, J. E., Hedges, L. V., \& Shadish, W. R. (2014). Designcomparable effect sizes in multiple baseline designs: A general modeling framework. Journal of Educational and Behavioral Statistics, 39(5), 368-393. https://doi.org/10.3102/1076998614 547577

- Rahman, A., Divan, G., Hamdani, S. U., Vajaratkar, V., Taylor, C., Leadbitter, K., Aldred, C., Minhas, A., Cardozo, P., Emsley, R., Patel, V., \& Green, J. (2016). Effectiveness of the parent-mediated intervention for children with autism spectrum disorder in south Asia in India and Pakistan (PASS): A randomised controlled trial. Lancet Psychiatry, 3(2), 128-136. https://doi.org/ 10.1016/s2215-0366(15)00388-0

- Randolph, J. K., Stichter, J. P., Schmidt, C. T., \& O'Connor, K. V. (2011). Fidelity and effectiveness of PRT implemented by caregivers without college degrees. Focus on Autism and Other Developmental Disabilities, 26(4), 230-238. https://doi.org/10. $1177 / 1088357611421503$ 
Reichow, B., Hume, K., Barton, E. E., \& Boyd, B. A. (2018). Early intensive behavioral intervention (EIBI) for young children with autism spectrum disorders (ASD). Cochrane Database of Systematic Reviews. https://doi.org/10.1002/14651858.CD009260. pub3

Reynell, J. K., \& Curwen, M. P. (1977). Reynell developmental language scales. NFER Publishing Co.

Roberts, J., Williams, K., Carter, M., Evans, D., Parmenter, T., Silove, N., Clark, T., \& Warren, A. (2011). A randomised controlled trial of two early intervention programs for young children with autism: Centre-based with parent program and home-based. Research in Autism Spectrum Disorders, 5(4), 1553-1566. https://doi.org/10.1016/j.rasd.2011.03.001

- Rocha, M. L., Schreibman, L., \& Stahmer, A. C. (2007). Effectiveness of training parents to teach joint attention in children with autism. Journal of Early Intervention, 29(2), 154-172. https:// doi.org/10.1177/105381510702900207

- Rogers, S. J., Estes, A., Lord, C., Munson, J., Rocha, M., \& , Winter, J., Greenson, J., Colombi, C. Dawson, G., Vismara, L. A., Sugar, C. A., Hellemann, G., Whelan, F., \& Talbott, M. (2019). A multisite randomized controlled two-phase trial of the Early Start Denver Model compared to treatment as usual. Journal of the American Academy of Child \& Adolescent Psychiatry, 58(9), 853-865. https://doi.org/10.1016/j.jaac.2019.01.004

- Rogers, S. J., Estes, A., Lord, C., Vismara, L., Winter, J., Fitzpatrick, A., Guo, M., \& Dawson, G. (2012). Effects of a brief Early Start Denver Model (ESDM)-based parent intervention on toddlers at risk for autism spectrum disorders: A randomized controlled trial. Journal of the American Academy of Child \& Adolescent Psychiatry, 51(10), 1052-1065. https://doi.org/10.1016/j.jaac. 2012.08.003

Roid, G. H., \& Miller, L. J. (1997). Leiter international performance scale - revised. Western Psychological Services.

- Rollins, P. R., Campbell, M., Hoffman, R. T., \& Self, K. (2016). A community-based early intervention program for toddlers with autism spectrum disorders. Autism, 20(2), 219-232. https://doi. org/10.1177/1362361315577217

Rothstein, H. R. (2008). Publication bias as a threat to the validity of meta-analytic results. Journal of Experimental Criminology, 4, 61-81. https://doi.org/10.1007/s11292-007-9046-9

- Russell, C. (2014). Brief PRT parent training for a rural, low-income family with three young children with autism: A mixed-methods case study. (Publication No. AAI3599235). [Doctoral dissertation, Indiana University]. ProQuest.

Rutter, M., Bailey, A., \& Lord, C. (2003). Social communication questionnaire. Western Psychological Services.

Ryberg, K. H. (2015). Evidence for the implementation of the Early Start Denver Model for young children with autism spectrum disorder. Journal of the American Psychiatric Nurses Association, 21(5), 327-337. https://doi.org/10.1177/1078390315608165

Sameroff, A., \& Chandler, M. (1975). Reproductive risk and the continuum of caretaking casualty. In M. H. M. Hetherington, S. Scarr-Salapatek, \& G. Siegel (Eds.), Review of child development research (pp. 187-244). University Park Press.

Sandbank, M., Bottema-Beutel, K., Crowley, S., Cassidy, M., Dunham, K., Feldman, J. I., Crank, J., Albarran, S. A., Raj, S., \& Mahbub, P. (2020a). Project AIM: Autism intervention meta-analysis for studies of young children. Psychological Bulletin, 146(1), 1-29. https://doi.org/10.1037/bul0000215

Sandbank, M., Bottema-Beutel, K., Crowley, S., Cassidy, M., Feldman, J. I., Canihuante, M., \& Woynaroski, T. (2020b). Intervention effects on language in children with autism: A project AIM meta-analysis. Journal of Speech, Language, and Hearing Research, 63(5), 1537-1560. https://doi.org/10.1044/2020_ JSLHR-19-00167
Schertz, H. H. (2005). Precursors of joint attention video coding measures. USA: Indiana University.

- Schertz, H. H., \& Odom, S. L. (2007). Promoting joint attention in toddlers with autism: A parent-mediated developmental model. Journal of Autism \& Developmental Disorders, 37(8), 15621575. https://doi.org/10.1007/s10803-006-0290-z

- Schertz, H. H., Odom, S., Baggett, K. M., \& Sideris, J. H. (2013). Effects of Joint Attention Mediated Learning for toddlers with autism spectrum disorders: An initial randomized controlled study. Early Childhood Research Quarterly, 28(2), 249-258. https://doi.org/10.1016/j.ecresq.2012.06.006

- Schertz, H. H., Odom, S. L., Baggett, K. M., \& Sideris, J. H. (2018). Mediating parent learning to promote social communication for toddlers with autism: Effects from a randomized controlled trial. Journal of Autism and Developmental Disorders, 48(3), 853-867. https://doi.org/10.1007/s10803-017-3386-8

Schopler, E., Reichler, R., \& Renner, B. R. (1993). Childhood autism rating scale. Western Psychological Services.

Schopler, E., Van Bourgondien, M., Wellman, G., \& Love, S. (2010). The Child Autism Rating Scale-Second Edition (CARS2). Western Psychological Services.

Schreibman, L., Dawson, G., Stahmer, A. C., Landa, R., Rogers, S. J., McGee, G. G., Kasari, C., Ingersoll, B., Kaiser, A. P., \& Bruinsma, Y. (2015). Naturalistic developmental behavioral interventions: Empirically validated treatments for autism spectrum disorder. Journal of Autism and Developmental Disorders, 45(8), 2411-2428. https://doi.org/10.1007/s10803-013-1972-y

- Schreibman, L., \& Stahmer, A. C. (2014). A randomized trial comparison of the effects of verbal and pictorial naturalistic communication strategies on spoken language for young children with autism. Journal of Autism and Developmental Disorders, 44(5), 1244-1251. https://doi.org/10.1007/s10803-013-1972-y

Semel, E., Wiig, E., \& Secord, W. (2006). Clinical evaluation of language fundamentals, 7th ed, Australian standardised ed. (CELF-4 Australian). Pearson, 2006.

Shadish, W. R., Hedges, L. V., Horner, R. H., \& Odom, S. L. (2015). The role of between-case effect size in conducting, interpreting, and summarizing single-case research. Kimberley: NCER 2015-002 National Center for Education Research.

Shadish, W. R., Zelinsky, N. A., Vevea, J. L., \& Kratochwill, T. R. (2016). A survey of publication practices of single-case design researchers when treatments have small or large effects. Journal of Applied Behavior Analysis, 49(3), 656-673. https://doi. org/10.1002/jaba.308

Sigman, M., \& Ruskin, E. (1999). Continuity and change in the social competence of children with autism, Down syndrome, and developmental delays. Monographs of the Society for Research in Child Development, 64(1), 114-257.

- Siller, M., Hutman, T., \& Sigman, M. (2013). A parent-mediated intervention to increase responsive parental behaviors and child communication in children with ASD: A randomized clinical trial. Journal of Autism and Developmental Disorders, 43(3), 540-555. https://doi.org/10.1007/s10803-012-1584-y

Sparrow, S. S., Balla, D. A., \& Cicchetti, P. U. (1984). Vineland Adaptive Behavior Scales. American Guidance Service.

Sparrow, S., Cicchetti, D., \& Balla, M. (2005). Vineland-II: Vineland Adaptive Behavior Scales. American Guidance Service.

Stone, W. L., Coonrod, E. E., Pozdol, S. L., \& Turner, L. M. (2003). The Parent Interview for Autism-Clinical Version (PIA-CV): A measure of behavioral change for young children with autism. Autism, 7(1), 9-30. https://doi.org/10.1177/136236130300700 1017

Stone, W. L., Ousley, O. Y., \& Littleford, C. D. (1997). Motor imitation in young children with autism: What's the object? Journal of Abnormal Child Psychology, 25(6), 475-485. https://doi. org/10.1023/A:1022685731726 
- Sullivan, K. (2014). The Early Start Denver Model: Outcomes and moderators of an intervention for toddlers with autism. (Publication No. AAI3599815). [Doctoral dissertation, University of Washington]. ProQuest.

Sundberg, M. L. (2008). Verbal Behavior Milestones Assessment and Placement Program (VB-MAPP). AVB.

- Sze, K. M. S. (2007). Using a high-probability behavioral momentum sequence to teach functional vocabulary to children with autism. (Publication No. AAI3226277). [Doctoral dissertation, University of California, Santa Barbara]. ProQuest.

Tager-Flusberg, H., \& Joseph, R. M. (2003). Identifying neurocognitive phenotypes in autism. Philosophical Transactions of the Royal Society of London Series b: Biological Sciences, 358(1430), 303-314. https://doi.org/10.1098/rstb.2002.1198

Tager-Flusberg, H., \& Kasari, C. (2013). Minimally verbal schoolaged children with autism spectrum disorder: The neglected end of the spectrum. Autism Research, 6(6), 468-478. https:// doi.org/10.1002/aur.1329

Tager-Flusberg, H., Paul, R., \& Lord, C. E. (2005). Language and communication in autism. In F. Volkmar, R. Paul, A. Klin, \& D. J. Cohen (Eds.), Handbook of autism and pervasive developmental disorder (3rd ed., Vol. 1, pp. 335-364). Wiley.

Tanner-Smith, E. E., \& Tipton, E. (2014). Robust variance estimation with dependent effect sizes: Practical considerations including a software tutorial in Stata and SPSS. Research Synthesis Methods, 5(1), 13-30. https://doi.org/10.1002/jrsm.1091

- Therrien, M. C. S., \& Light, J. C. (2018). Promoting peer interaction for preschool children with complex communication needs and autism spectrum disorder. American Journal of SpeechLanguage Pathology, 27(1), 207-221. https://doi.org/10.1044/ 2017_ajslp-17-0104

- Thiemann, K. S., \& Goldstein, H. (2004). Effects of peer training and written text cueing on social communication of school-age children with pervasive developmental disorder. Journal of Speech Language Hearing Research, 47(1), 126-144. https://doi.org/10. 1044/1092-4388(2004/012)

- Thiemann-Bourque, K. S., McGuff, S., \& Goldstein, H. (2017). Training peer partners to use a speech-generating device with classmates with autism spectrum disorder: Exploring communication outcomes across preschool contexts. Journal of Speech, Language, and Hearing Research, 60(9), 2648-2662. https://doi. org/10.1044/2017_JSLHR-L-17-0049

Thurm, A., Lord, C., Lee, L.-C., \& Newschaffer, C. (2007). Predictors of language acquisition in preschool children with autism spectrum disorders. Journal of Autism and Developmental Disorders, 37(9), 1721-1734. https://doi.org/10.1007/s10803-006-0300-1

- Turner-Brown, L., Hume, K., Boyd, B. A., \& Kainz, K. (2019). Preliminary efficacy of family implemented TEACCH for toddlers: Effects on parents and their toddlers with autism spectrum disorder. Journal of Autism and Developmental Disorders, 49(7), 2685-2698. https://doi.org/10.1007/s10803-016-2812-7

Užgiris, I. Č, \& Hunt, J. M. (1975). Assessment in infancy: Ordinal scales of psychological development. USA: University of Illinois Press.

Valentine, J. C., Tanner-Smith, E. E., Pustejovsky, J. E., \& Lau, T. (2016). Between-case standardized mean difference effect sizes for single-case designs: A primer and tutorial using the scdhlm web application. Campbell Systematic Reviews, 12(1), 1-31.

- Venker, C. E., \& McDuffie., A. S., Ellis Weismer, S., \& Abbeduto, L. (2012). Increasing verbal responsiveness in parents of children with autism: A pilot study. Autism, 16(6), 568-585. https://doi. org/10.1177/1362361311413396

- Vernon, T. W., Holden, A. N., Barrett, A. C., Bradshaw, J., Ko, J. A., McGarry, E. S., Horowitz, E. J., Tagavi, D. M., \& German, T. C. (2019). A pilot randomized clinical trial of an enhanced pivotal response treatment approach for young children with autism: The
PRISM model. Journal of Autism and Developmental Disorders, 49(6), 2358-2373. https://doi.org/10.1007/s10803-019-03909-1

- Vernon, T., Koegel, R. L., Dauterman, H., \& Stolen, K. (2012). An early social engagement intervention for young children with autism and their parents. Journal of Autism \& Developmental Disorders, 42(12), 2702-2717. https://doi.org/10.1007/ s10803-012-1535-7

Verschuur, R., Didden, R., Lang, R., Sigafoos, J., \& Huskens, B. (2014). Pivotal response treatment for children with autism spectrum disorders: A systematic review. Review Journal of Autism and Developmental Disorders, 1(1), 34-61. https://doi.org/10. 1007/s10803-016-2966-3

Vivanti, G., Paynter, J., Duncan, E., Fothergill, H., Dissanayake, C., Rogers, S. J., \& Team, V. A (2014). Effectiveness and feasibility of the Early Start Denver Model implemented in a group-based community childcare setting. Journal of Autism and Developmental Disorders, 44(12), 3140-3153 https://doi.org/10.1007/ s10803-014-2168-9

- Vogler-Elias, D. (2009). A parent-implemented shared storybook reading intervention for preschoolers with autism spectrum disorders. (Publication No. AAI3356090). [Doctoral dissertation, State University of New York at Buffalo]. ProQuest.

Warlaumont, A. S., Richards, J. A., Gilkerson, J., \& Oller, D. K. (2014). A social feedback loop for speech development and its reduction in autism. Psychology Science, 25(7), 1314-1324. https://doi.org/ 10.1177/0956797614531023

Warren, S. F., Fey, M. E., \& Yoder, P. J. (2007). Differential treatment intensity research: A missing link to creating optimally effective communication interventions. Mental Retardation and Developmental Disabilities Research Reviews, 13(1), 70-77. https://doi. org/10.1002/mrdd.20139

- Warreyn, P., \& Roeyers, H. (2014). See what I see, do as I do: Promoting joint attention and imitation in preschoolers with autism spectrum disorder. Autism, 18(6), 658-671. https://doi.org/10. $1177 / 1362361313493834$

Wechsler, D. (2012). Wechsler Preschool and Primary Scale of Intelligence-Fourth Edition. Pearson Assessments.

Wetherby, A. M., \& Prizant, B. M. (2002). Communication and Symbolic Behaviour Scales Developmental Profile. Brookes Publishing.

- Whalen, C. (2001). Joint attention training for children with autism and the collateral effects on language, play, imitation, and social behaviors. (Publication No. AAI9995991). [Doctoral dissertation, University of California, San Diego]. ProQuest.

- Whalen, C., \& Schreibman, L. (2003). Joint attention training for children with autism using behavior modification procedures. Journal of Child Psychology and Psychiatry, 44(3), 456-468. https://doi.org/10.1111/1469-7610.00135

What Works Clearinghouse. (2016). Study review guide instructions for reviewing single-case design studies. https://ies.ed.gov/ncee/ wwc/Docs/ReferenceResources/wwc_srg_scd_instructions_s3_ v2.pdf.

Wilkinson, K. M. (1998). Profiles of language and communication skills in autism. Mental Retardation and Developmental Disabilities Research Reviews, 4(2), 73-79.

Williams, K. T. (1997). Expressive Vocabulary Test. American Guidance Services, Inc.

Williams, K. T. (2007). Expressive Vocabulary Test-Second Edition. Pearson.

- Wong, C. S. (2013). A play and joint attention intervention for teachers of young children with autism: A randomized controlled pilot study. Autism, 17(3), 340-357. https://doi.org/10.1177/13623 61312474723

Yoder, P. J., Bottema-Beutel, K., Woynaroski, T., Chandrasekhar, R., \& Sandbank, M. (2013). Social communication intervention effects vary by dependent variable type in preschoolers with autism 
spectrum disorders. Evidence-Based Communication Assessment and Intervention, 7(4), 150-174. https://doi.org/10.1080/ 17489539.2014.917780

Yoder, P. J., Lloyd, B. P., \& Symons, F. J. (2018). Observational measurement of behavior (2nd ed.). Brooks Publishing Company.

Yoder, P. J., \& Warren, S. F. (2002). Effects of prelinguistic milieu teaching and parent responsivity education on dyads involving children with intellectual disabilities. Journal of Speech, Language, and Hearing Research, 45(6), 1158-1174. https://doi.org/ 10.1044/1092-4388(2002/094)

- Zimmer, K. (2015). Efficacy of caregiver training to establish joint attention of children with Autism. (Publication No. AAI3586657). [Doctoral dissertation, University of Florida]. ProQuest.
Zimmerman, I. L., Steiner, V. G., \& Pond, R. E. (2002). Preschool Language Scale - Fourth Edition. Psychological Corporation.

Zimmerman, I. L., Steiner, V. G., \& Pond, R. A. (2011). Preschool Language Scale - Fifth Edition. Psychological Corporation.

Publisher's Note Springer Nature remains neutral with regard to jurisdictional claims in published maps and institutional affiliations. 